\title{
Epigenetic Modifications in Head and Neck Cancer
}

\section{Jadwiga Gaździcka ${ }^{1}$ (D) . Karolina Gołąbek ${ }^{1}$ (D) . Joanna Katarzyna Strzelczyk ${ }^{1}$ (D) . Zofia Ostrowska ${ }^{1}$ (D)}

Received: 21 May 2019 / Accepted: 24 October 2019 / Published online: 11 November 2019

(c) The Author(s) 2019

\section{Abstract}

Head and neck squamous cell carcinoma (HNSCC) is the sixth most common human malignancy in the world, with high mortality and poor prognosis for patients. Among the risk factors are tobacco and alcohol intake, human papilloma virus, and also genetic and epigenetic modifications. Many studies show that epigenetic events play an important role in HNSCC development and progression, including DNA methylation, chromatin remodeling, histone posttranslational covalent modifications, and effects of non-coding RNA. Epigenetic modifications may influence silencing of tumor suppressor genes by promoter hypermethylation, regulate transcription by microRNAs and changes in chromatin structure, or induce genome instability through hypomethylation. Moreover, getting to better understand aberrant patterns of methylation may provide biomarkers for early detection and diagnosis, while knowledge about target genes of microRNAs may improve the therapy of HNSCC and extend overall survival. The aim of this review is to present recent studies which demonstrate the role of epigenetic regulation in the development of HNSCC.

Keywords HNSCC $\cdot$ Squamous cell carcinoma $\cdot$ Epigenetics $\cdot$ Methylation · MicroRNA $\cdot$ Histone modification

\section{Introduction}

Epigenetic modifications can be defined as heritable, reversible changes in gene expression which do not result from a change in the sequence of DNA bases (Momparler 2003; Teodoridis et al. 2004; Castilho et al. 2017). Therefore, epigenetic mechanisms change the phenotype without interference in DNA sequences (Arantes et al. 2014). Epigenetic processes include DNA methylation, histone

Jadwiga Gaździcka

jgazdzicka@sum.edu.pl

1 Department of Medical and Molecular Biology, Faculty of Medical Sciences in Zabrze, Medical University of Silesia, Jordana 19 Str., 41-808 Zabrze, Katowice, Poland 
posttranslational covalent modifications, changes in chromatin structure, and effects of non-coding RNAs (Arantes et al. 2014; Castilho et al. 2017). An epigenetic pattern may be modulated by external factors such as diet, alcohol, tobacco, toxins, or pharmaceutical treatment (Ghantous et al. 2018). Epigenetic mechanisms are associated with carcinogenesis of numerous cancers (Park et al. 2011; Osorio and Castillo 2016) and play an important role in the development of head and neck squamous cell carcinoma (HNSCC).

HNSCC is placed at sixth of the most frequent human malignancies and belongs to the most aggressive cancers. Worldwide, more than half a million new cases are diagnosed per year and nearly $50 \%$ of them have a less than 5-year survival rate (Leemans et al. 2011; Ganci et al. 2012; Magić et al. 2013). Cancer cells spread to the oral cavity, larynx, naso-, hypo-, and oro-pharynx. Environmental and genetic factors influence the development of HNSCC and the main lifestyle risk factors include Human Papilloma Virus (HPV) infection, age, diet, tobacco use, and alcohol intake (Demokan and Dalay 2011; Magić et al. 2013; Koffler et al. 2014). External factors like alcohol abuse and tobacco influence epigenetic patterns in some types of HNSCC like oral cancer (Ghantous et al. 2018).

In this review, we summarize the main epigenetic modifications associated with HNSCC.

\section{Methylation of DNA}

DNA methylation, the covalent addition of a methyl group $\left(\mathrm{CH}_{3}\right)$ to carbon in the 5 position of cytosine in the sequence $5^{\prime}-\mathrm{CG}-3^{\prime}$, is one of the most common epigenetic mechanisms (Fig. 1) (Momparler 2003; Luczak and Jagodziński 2006; Gopisetty et al. 2006; Magić et al. 2013). The targets of methylation may be in any type of DNA sequence such as intergenic DNA, genes, or non-coding repetitive sequences (Reyngold and Chan 2018). However, in the genome CpG dinucleotides are arranged asymmetrically; in normal cells single CpGs are highly methylated, while CpG islands (CGIs), 0.5-4 kb regions of DNA which content 60-70\% of CG dinucleotides, are usually unmethylated. Approximately $50 \%$ of genes contain CGIs
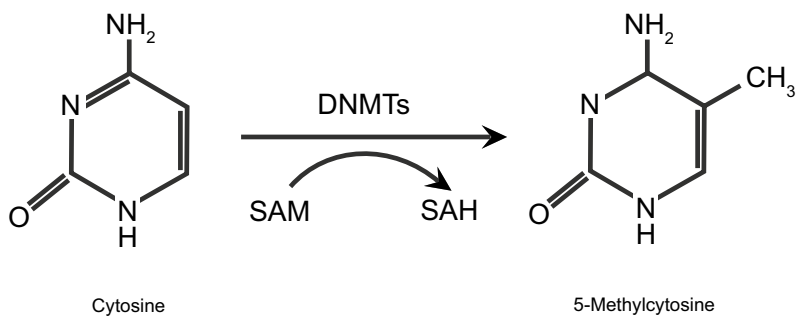

Fig. 1 DNA methylation. DNMTs add a methyl group $\left(\mathrm{CH}_{3}\right)$ to the carbon in the 5 position of cytosine, converting it to 5-methylcytosine. The donor of the methyl group is S-adenosylmethionine (SAM), which is converted to S-adenosylhomocysteine (SAH) (updated from Luczak and Jagodziński 2006; Osorio and Castillo 2016) 
in their promoter regions (Luczak and Jagodziński 2006; Magić et al. 2013; Reyngold and Chan 2018) and methylation mostly occurs in the promoter region or the first exon sequence (Luczak and Jagodziński 2006; Gopisetty et al. 2006; Arantes et al. 2014). Methylation is catalyzed by members of the family of DNA methyltransferases (DNMTs) composed of DNMT1, DNMT2, DNMT3A, and DNMT3B. DNMT1 is a maintenance enzyme responsible for methylation during replication, while de novo methylation is catalyzed by DNMT3A and DNMT3B (Luczak and Jagodziński 2006; Arantes et al. 2014). The DNMT family enzymes use S-adenosylmethionine (SAM) as a methyl donor, which is converted to S-adenosylhomocysteine (SAH) (Luczak and Jagodziński 2006; Osorio and Castillo 2016).

Methylation is an important process to regulate gene expression, especially in silenced genes located on the inactivated $\mathrm{X}$ chromosome in females and in genomic imprinting (Luczak and Jagodziński 2006; Park et al. 2011; Arantes et al. 2014; Reyngold and Chan 2018). Aberrant patterns of methylation have been reported in various cancers, and two different patterns of methylation are present. The first is genome-wide hypomethylation, and the second is hypermethylation of CGIs located in the promoter region of genes. Global hypomethylation is connected with chromosomal instability and gene activation, while increased methylation in promoter regions concerns mostly tumor suppressor genes and in consequence reduces their expressions (Gopisetty et al. 2006; Arantes et al. 2014).

\section{Hypomethylation}

Global DNA hypomethylation in repeat sequences, transposons, gene deserts or CpG dinucleotides located in introns may influence genome instability (Ehrlich 2009; Hatziapostolou and Iliopoulos 2011). In the other hand, it may stimulate activation of oncogenes or latent viruses (Magić et al. 2013; Castilho et al. 2017). Hypomethylation of promoters of genes or retrotransposons has been documented in studies of HNSCC. Lower methylation in retrotransposon elements, like long interspersed elements (LINEs) or short interspersed elements (SINEs), influences carcinogenesis through genome destabilization. In normal mammalian cells LINE sequences have a high methylation status, while during cancer development they are hypomethylated, which contributes to activating transcription of sequences which influence genome instability and as a result may facilitate carcinogenesis (Luczak and Jagodziński 2006; Reyngold and Chan 2018). LINE-1 (long interspersed nucleotide element-1) has decreased methylation in various cancer cells compared to normal cells, and meta-analysis shows that this hypomethylation is associated with advanced cancer (Kitkumthorn and Mutirangura 2011). In addition, another metaanalysis, based on 20 studies concerning methylation of repeated sequences such as LINE, Alu, and Sat- $\alpha$ as prognostic markers for various cancers, suggests that the level of global DNA hypomethylation is connected with a dismal prognosis (Li et al. 2014b). Several studies show hypomethylation of LINEs or SINEs in head and neck cancer (Richards et al. 2009; Subbalekha et al. 2009; Chaisaingmongkol et al. 2012). Hypomethylation of Alu, one of the SINEs, was confirmed by Puttipanyalears et al. (2013), who reported that in oral cancer among the Asian population the Alu 
methylation decreased with advanced stages of cancer. Foy et al. (2015) showed that in patients with premalignant oral lesions, LINE sequences are hypomethylated and associated with increased risk for oral carcinogenesis. Furthermore, LINE-1 sequences are hypomethylated in oral squamous cell carcinoma (OSCC), but independently of the tumor's clinical stage and location (Subbalekha et al. 2009), as well as in oropharyngeal squamous cell carcinoma (OPSCC) (Furlan et al. 2017). Interestingly, OPSCC patients with LINE-1 hypomethylation have a 3.5-fold higher risk of early relapse compared to cases with higher methylation (Furlan et al. 2017). On the other hand, Smith et al. (2007) showed that LINE-1 hypomethylation occurs in $67 \%$ of HNSCC cases examined and that global hypomethylation is connected with an advanced stage of the tumor using ANOVA, although this correlation was not significant by multivariate analysis. Arayataweegool et al. (2019) utilized cocultures of HNSCC cell lines and peripheral blood mononuclear cells (PBMCs) to measure the methylation level of LINE-1 in PBMCs, and found that this level is significantly downregulated in coculture with cancer cells due to factors secreted by HNSCCs, an effect which could be used for HNSCC diagnostics. Kitkumthorn et al. (2012) measured the methylation level of LINE-1 and Alu sequences in lymph node (LN) metastases of HNSCC patients and confirmed their lower methylation in HNSCC samples with metastasis; however, only hypomethylation of LINE-1 was statistically significant and furthermore the decreases of methylation levels were not associated with the stage and grade of tumors. It has been also reported that global hypomethylation is characteristic for patients with tongue squamous cell carcinoma (TSCC) and, interestingly, is connected with female gender. In addition, Chen et al. (2016a) observed associations between decreased methylation and poor survival for TSCC patients, predominantly for female, older patients with a stage I or II AJCC (American Joint Committee on Cancer) cancer without lymph node involvement and with postoperative radiotherapy. On the other hand, Morandi et al. (2017) observed no signs of hypomethylation in OSCC. Hypomethylation in promoter regions of genes has been shown in several studies of HNSCC (Table 1).

\section{Hypermethylation}

In normal cells, CGIs are poorly methylated in transcriptionally active genes, while a high level of methylation in promoters of genes is characteristic for epigenomes of cancer cells (Castilho et al. 2017; Reyngold and Chan 2018). This hypermethylation of CGIs may lead to transcriptional silencing of tumor suppressor genes and in consequences promote malignant transformation (Fig. 2) (Herman and Baylin 2003; Magić et al. 2013). Hypermethylation of promoter regions in head and neck cancer has been shown in many studies, and below we summarize recent studies about $p 16$, $P T E N, D A P K, M G M T, E C A D$ and RASSF1 genes which are frequently analyzed in HNSCC. Genes which are less common hypermethylated in HNSCC are presented in Table 2.

The gene p16 (CDKN2A) is a known tumor suppressor gene, which inhibits cyclin-dependent kinases and cell cycle progression (Magić et al. 2013; Padhi et al. 2017). Hypermethylation of its promoter is a common finding in HNSCC studies 
Table 1 Selected genes which are hypomethylated in HNSSC

\begin{tabular}{llll}
\hline Gene & Cancer & Observed connections with hypomethylation & References \\
\hline WSIP1 & OSCC & $\begin{array}{c}\text { Higher expression of WSIP1 protein character- } \\
\text { istic for patients with lymph node metastasis }\end{array}$ & Clausen et al. (2016) \\
CSPG4 & HNSCC & $\begin{array}{l}\text { Worse clinical outcome } \\
\text { Overexpression of mRNA and protein }\end{array}$ & Warta et al. (2014) \\
PD-L1 & HNSCC & Overexpression of PD-L1 protein & Franzen et al. (2018) \\
$P D-L 2$ & HNSCC & Upregulation of PD-L2 mRNA expression & Franzen et al. (2018) \\
$I L 6$ & OSCC & Upregulation of gene expression & Basu et al. (2017) \\
$P T P N 22$ & OSCC & Upregulation of gene expression & Basu et al. (2017) \\
$R U N X 1$ & OSCC & Upregulation of gene expression & Basu et al. (2017) \\
$C D 28$ & OSCC & Upregulation of gene expression & Basu et al. (2017) \\
$C D 22$ & OSCC & No data related to gene expression & Basu et al. (2017) \\
$C D 80$ & OSCC & Upregulation of gene expression & Basu et al. (2017) \\
$T L R 1$ & OSCC & Upregulation of gene expression & Basu et al. (2017) \\
$T N F a$ & OSCC & Upregulation of gene expression & Basu et al. (2017) \\
$A P E X 2$ & HNSCC & Decreased mRNA expression in tumor & Chaisaingmongkol et al. (2012) \\
$T R E X 2$ & HNSCC & No data related to gene expression & Chaisaingmongkol et al. (2012) \\
$M S H 4$ & HNSCC & Decreased mRNA expression in tumor & Chaisaingmongkol et al. (2012) \\
$M I R 296$ & OSCC & No date related to gene expression & Morandi et al. (2017) \\
$T E R T$ & OSCC & No date related to gene expression & Morandi et al. (2017) \\
$G P 1 B B$ & OSCC & No date related to gene expression & Morandi et al. (2017) \\
\hline
\end{tabular}

Normal cell
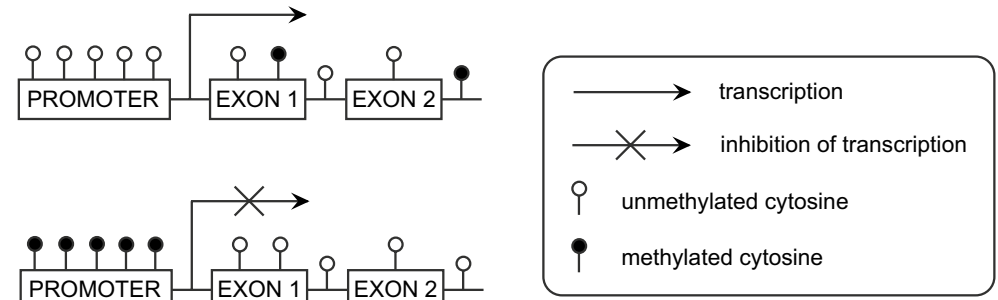

Cancer cell

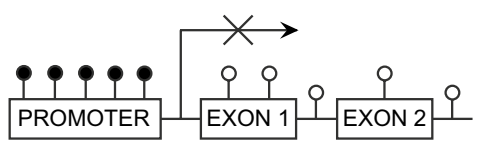

Fig. 2 Methylation of promoter region of genes in normal and cancer cells (updated from Hatziapostolou and Iliopoulos 2011; Reyngold and Chan 2018)

and meta-analyses (Sanchez-Cespedes et al. 2000; Don et al. 2014; Choudhury and Ghosh 2015; Sushma et al. 2016; Dvojakovska et al. 2018; Alsofyani et al. 2017; Veeramachaneni et al. 2019). Allameh et al. (2018) reported a higher methylation level of its promoter in OSCC patients compared to a control group, and hypermethylation was associated with lower expression of that gene in tumor samples. A metaanalysis comparing 67 case control studies confirms the higher methylation of the p16 promoter region in HNSCC than in normal controls, and shows that the methylation level increases progressively from the control group to patients with premalignant lesions and then to HNSCC patients, respectively. Hypermethylation was 


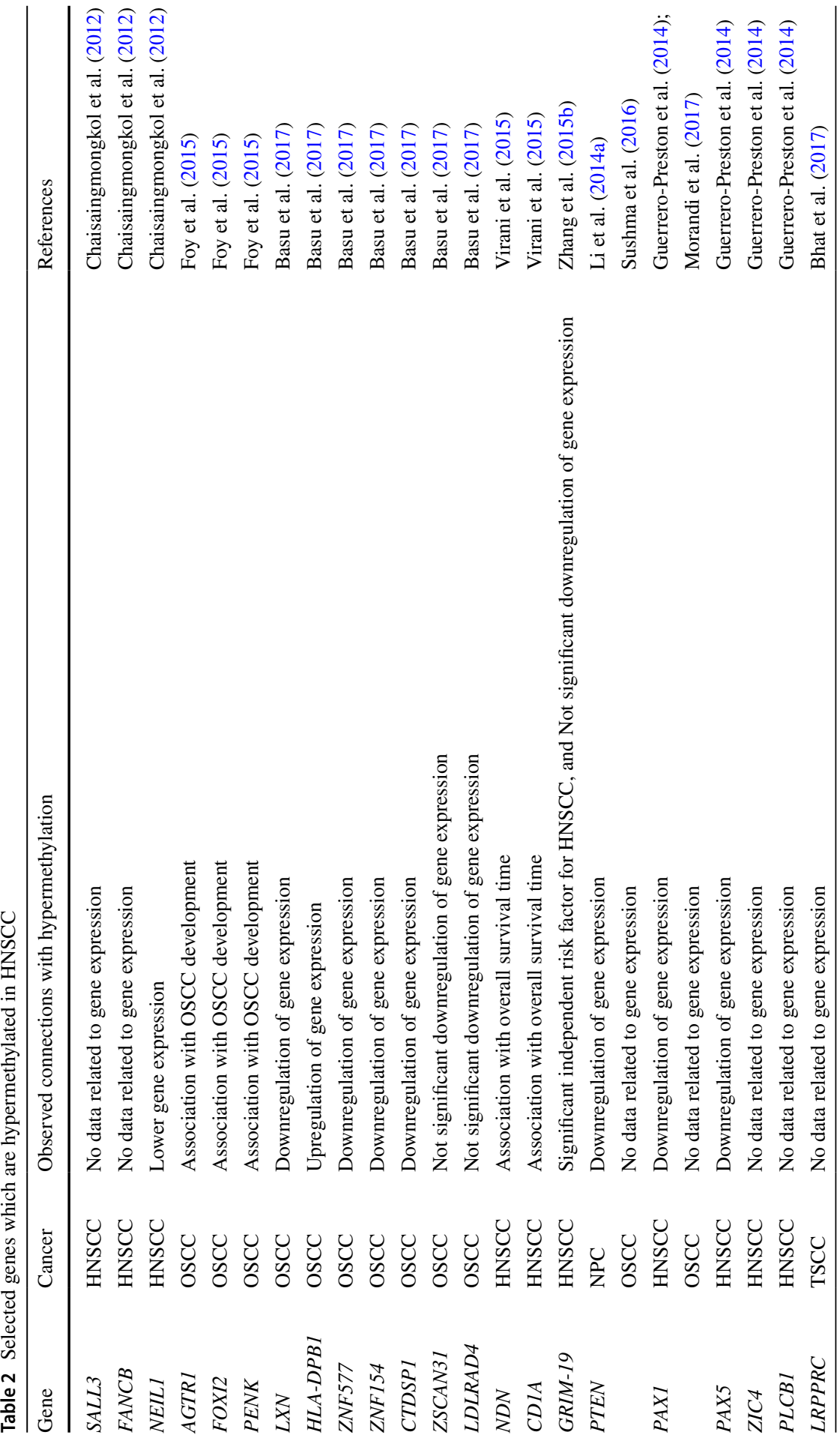




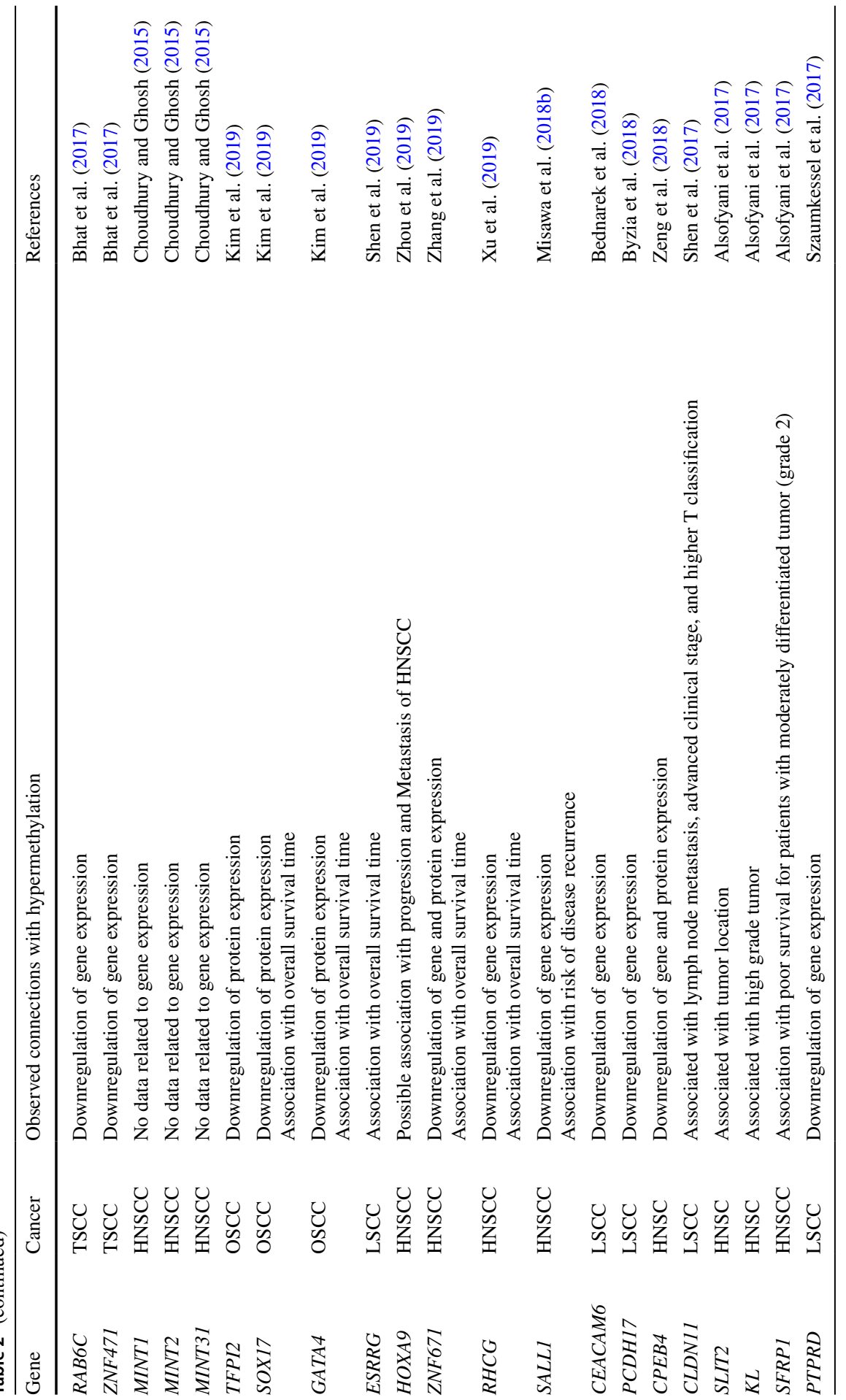


associated with male gender as well as with LN metastasis. Methylated $C D K N 2 A$ may therefore be a useful marker in diagnosis and prognosis for head and neck cancer (Zhou et al. 2018).

Another hypermethylated tumor suppressor gene in HNSCC is phosphatase and tensin homolog $(P T E N)$, which negatively regulates Akt signaling and in consequence decreases cell proliferation (Sushma et al. 2016). Several studies reported hypermethylation in the promoter of PTEN in oral cancer (Alyasiri et al. 2013; Sushma et al. 2016), and nasopharyngeal cancer (Li et al. 2014a). Moreover, in OSCC, this increased methylation is associated with well-differentiated tumors and with age of under 50 years among an Indian population; no correlation was found between methylation and gender (Alyasiri et al. 2013). Increased methylation in the PTEN promoter in NPC tissues and NPC cell lines is connected with down-regulation of PTEN (Li et al. 2014a) and lower expression of PTEN mRNA in OSCCderived cell lines (Tanzawa et al. 2008).

Death-associated protein kinase $(D A P K)$, a tumor suppressor gene, is also hypermethylated in head and neck cancer (Sanchez-Cespedes et al. 2000; Choudhury and Ghosh 2015), and hypermethylation is positively correlated with LN metastases and with stages III and IV of HNSCC (Sanchez-Cespedes et al. 2000), as well as inversely correlated with lower expression of $D A P K$ in tongue cancer (Bhat et al. 2017). A meta-analysis of eighteen studies confirmed that methylation of the DAPK promoter is over fourfold higher in HNSCC patients compared to healthy controls (Cai et al. 2017), while another meta-analysis confirmed DAPK promoter hypermethylation among OSCC patients (Don et al. 2014) as well as an association with a higher risk of nasopharyngeal carcinoma (Zhang et al. 2018a). The DAPK promoter is also more highly methylated in OSCC samples compared to matched surgical margins, and interestingly is associated with LN metastasis and older age of HNSCC patients (Strzelczyk et al. 2019).

The gene MGMT (O6-methylguanine-DNA methyltransferase) is related to DNA repair, and increased methylation in its promoter has been reported in HNSCC (Koutsimpelas et al. 2012; Chaisaingmongkol et al. 2012; Dvojakovska et al. 2018). In a meta-analysis based on 20 studies, the promoter of MGMT was hypermethylated in HNSCC compared to healthy controls, suggesting a connection between higher methylation and an increased risk of head and neck cancer (Cai et al. 2016). Metaanalysis of OSCC cases also confirmed higher methylation in this promoter (Don et al. 2014) and in addition, the increased methylation was connected with a lower level of MGMT protein (Koutsimpelas et al. 2012). Onerci Celebi et al. (2016) utilized a pyrosequencing technique to assay methylation level, and showed that hypermethylation of MGMT promoter is frequent in laryngeal cancer; however, without association with clinicopathological features of patients such as age, tumor stage or differentiation, and disease-free survival. Moreover, hypermethylation was found in HNSCC tumors compared to the surgical margins (Strzelczyk et al. 2018).

E-cadherin $(C D H 1, E C A D)$ is another tumor suppressor gene related to cell adhesion, and is frequently hypermethylated in HNSCC cases (Choudhury and Ghosh 2015; Strzelczyk et al. 2018). A meta-analysis based on 13 studies revealed that increased methylation of the promoter of $\mathrm{CDH} 1$ is associated with oral cancer risk (Wen et al. 2018), and it has been suggested that this hypermethylation is associated 
with lower expression of E-cadherin protein in OSCC patients (Pannone et al. 2014). In contrast, Domingos et al. (2017) showed no differences in the methylation level of $\mathrm{CDH} 1$ promoter between groups of patients with potentially malignant oral lesions, OSCC, and healthy controls; moreover, in most samples the $C D H 1$ gene promoter was unmethylated and in the OSCC group the level of methylation was not associated with clinicopathological features.

RASSF1 (Ras association domain-containing protein 1) is a tumor suppressor gene which plays an important role in cell cycle control, apoptosis, and cellular adhesion, and its inactivation is associated with development of many cancers (Donninger et al. 2007). In head and neck cancer, hypermethylation of RASSF1 promoter is a frequent event (Choudhury and Ghosh 2015) and meta-analysis shows that it is significantly associated with these cancers. It has been suggested that aberrant methylation of RASSF 1A may be a useful biomarker for HNSCC (Meng et al. 2016). Also, a recent meta-analysis of OSCC confirmed that promoter hypermethylation of RASSF1A is connected with oral cancer risk (Wen et al. 2018) although, Koutsimpelas et al. (2012) observed hypermethylation of RASSF $1 A$ in only $13 \%$ of tumor samples examined.

\section{HPV Status and Level of DNA Methylation}

Differences in methylation level occur between HPV(+) and HPV(-) HNSCC cases. In addition, HPV status influences aberrant methylation patterns in head and neck cancer independently of other external risk factors like smoking or alcohol (Degli Esposti et al. 2017). Several studies reported that HPV infection may be connected with hyper- or hypomethylation of genes, which are presented in Table 3.

\section{Smoking and Drinking Abuse and Their Potential Influence on DNA Methylation}

Exposure to smoke and alcohol influences methylation level (Ghantous et al. 2018). Methylation linked with exposure to smoke or alcohol is presented in Table 4.

\section{Methylation Enzymes}

A level of enzymes associated with methylation and demethylation processes and their activity may influence epigenetic regulation. Below we present the recent studies on DNMTs and TET enzymes and their connections with HNSCC.

\section{DNMT}

The level and activity of DNMTs may contribute to HNSCC development. DNMT3b is upregulated in esophageal squamous cell carcinoma, and associated with hypermethylation of multiple tumor-associated genes such as DAPK, p16, or CDH1 (Li et al. 2011). The mRNA expression of DNA methyltransferases (DNMT1, DNMT3a and DNMT3b) was upregulated also in OSCC. Moreover, overexpression of DNMT1 was an independent marker of poor clinical outcome and relapse-free 
Table 3 The level of methylation connected with HPV status

\begin{tabular}{|c|c|c|c|}
\hline Gene & HPV status & Methylation & References \\
\hline $\mathrm{CDH} 18$ & + & $\uparrow$ & Degli Esposti et al. (2017) \\
\hline CTNND2 & + & $\uparrow$ & Degli Esposti et al. (2017) \\
\hline ELMO1 & + & $\uparrow$ & Degli Esposti et al. (2017) \\
\hline $\mathrm{CDH} 8$ & + & $\uparrow$ & Degli Esposti et al. (2017) \\
\hline CRMP1 & + & $\uparrow$ & Degli Esposti et al. (2017) \\
\hline PCDH10 & + & $\uparrow$ & Degli Esposti et al. (2017) \\
\hline$M S X 2$ & + & $\uparrow$ & Degli Esposti et al. (2017) \\
\hline$S Y N 2$ & + & $\uparrow$ & Degli Esposti et al. (2017) \\
\hline PCDHB11 & + & $\uparrow$ & Degli Esposti et al. (2017) \\
\hline HTRlE & + & $\uparrow$ & Degli Esposti et al. (2017) \\
\hline CCNA1 & + & $\uparrow$ & $\begin{array}{l}\text { Colacino et al. (2013) and } \\
\text { Virani et al. (2015) }\end{array}$ \\
\hline$G R B 7$ & + & $\uparrow$ & Colacino et al. (2013) \\
\hline $\mathrm{CDH} 11$ & + & $\uparrow$ & Colacino et al. (2013) \\
\hline$R U N X 1 T 1$ & + & $\uparrow$ & Colacino et al. (2013) \\
\hline$S Y B L 1$ & + & $\uparrow$ & Colacino et al. (2013) \\
\hline TUSC3 & + & $\uparrow$ & Colacino et al. (2013) \\
\hline MINT31 & + & $\uparrow$ & Choudhury and Ghosh (2015) \\
\hline$N D N$ & + & $\uparrow$ & Virani et al. (2015) \\
\hline$C D 1 A$ & + & $\uparrow$ & Virani et al. (2015) \\
\hline$D C C$ & + & $\uparrow$ & Virani et al. (2015) \\
\hline$C A D M 1$ & + & $\uparrow$ & van Kempen et al. (2014) \\
\hline TIMP3 & + & $\uparrow$ & van Kempen et al. (2014) \\
\hline ADORA2 & + & $\uparrow$ & Vogt et al. (2018) \\
\hline$N C A N$ & + & $\downarrow$ & Degli Esposti et al. (2017) \\
\hline$N R X N 1$ & + & $\downarrow$ & Degli Esposti et al. (2017) \\
\hline COL19A1 & + & $\downarrow$ & Degli Esposti et al. (2017) \\
\hline$S Y C P 2$ & + & $\downarrow$ & Degli Esposti et al. (2017) \\
\hline$R P A 2$ & + & $\downarrow$ & Degli Esposti et al. (2017) \\
\hline$S M C 1 B$ & + & $\downarrow$ & Degli Esposti et al. (2017) \\
\hline$S P D E F$ & + & $\downarrow$ & Colacino et al. (2013) \\
\hline STAT5A & + & $\downarrow$ & Colacino et al. (2013) \\
\hline$M G M T$ & + & $\downarrow$ & Colacino et al. (2013) \\
\hline ESR2 & + & $\downarrow$ & Colacino et al. (2013) \\
\hline$J A K 3$ & + & $\downarrow$ & Colacino et al. (2013) \\
\hline HSD17B12 & + & $\downarrow$ & Colacino et al. (2013) \\
\hline \multirow[t]{2}{*}{ p16 } & + & $\downarrow$ & Virani et al. (2015) \\
\hline & + & $\uparrow$ & Choudhury and Ghosh (2015) \\
\hline \multirow[t]{2}{*}{ RASSF1 } & + & $\downarrow$ & Colacino et al. (2013) \\
\hline & + & $\uparrow$ & Choudhury and Ghosh (2015) \\
\hline NT5E & + & $\downarrow$ & Vogt et al. (2018) \\
\hline CHFR & - & $\uparrow$ & van Kempen et al. (2014) \\
\hline$P A X 1$ & - & $\uparrow$ & Guerrero-Preston et al. (2014) \\
\hline
\end{tabular}


Table 3 (continued)

\begin{tabular}{llll}
\hline Gene & HPV status & Methylation & References \\
\hline PAX5 & - & $\uparrow$ & Guerrero-Preston et al. (2014) \\
CDH13 & \pm & $\uparrow$ & van Kempen et al. (2014) \\
RARB & \pm & $\uparrow$ & van Kempen et al. (2014) \\
DAPK & \pm & $\uparrow$ & van Kempen et al. (2014) \\
& + & $\uparrow$ & Choudhury and Ghosh (2015) \\
LINE1 seguences & + & $\uparrow$ & Furlan et al. (2017) \\
& - & $\downarrow$ & Richards et al. (2009)
\end{tabular}

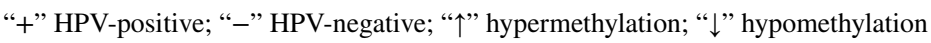

Table 4 Methylation linked with exposure to smoke or alcohol

\begin{tabular}{lllll}
\hline Gene & Smoke & Alcohol & Methylation & References \\
\hline NDN & + & No data & $\downarrow$ & Virani et al. (2015) \\
$C D 1 A$ & + & No data & $\downarrow$ & Virani et al. (2015) \\
DCC & + & No data & $\downarrow$ & Virani et al. (2015) \\
PAX1 & + & No data & $\uparrow$ & Guerrero-Preston et al. (2014) \\
PAX5 & \pm & No data & $\uparrow$ & Guerrero-Preston et al. (2014) \\
DAPK & + & No data & $\uparrow$ & Arantes et al. (2015) \\
& No correlation & + & Cai et al. (2017) \\
CADM1 & - & - & van Kempen et al. (2014) \\
TIMP3 & - & No correlation & $\uparrow$ & van Kempen et al. (2014) \\
RASSF1 & No correlation & No correlation & $\uparrow$ & Wen et al. (2018) \\
p16 & + & No data & $\uparrow$ & Allameh et al. (2018) \\
& No correlation & No correlation & $\uparrow$ & Sushma et al. (2016) \\
PTEN & No correlation & No correlation & $\uparrow$ & Sushma et al. (2016) \\
Alu seguences & + & No data & $\downarrow$ & Puttipanyalears et al. (2013) \\
Line1 sequences & No correlation & No correlation & $\downarrow$ & Smith et al. (2007) \\
& No correlation & No correlation & $\downarrow$ & Subbalekha et al. (2009) \\
\hline “" & & $\uparrow$ &
\end{tabular}

"+" used; "-" not used; “^” hypermethylation; “l” hypomethylation

survival of OSCC patients (Supic et al. 2017). Another study also confirmed upregulation of DNMT3a in OSCC, in connection with low expression of Klotho, the anti-aging gene (Adhikari et al. 2017). Chen et al. (2016b) revealed that in invasive subclone HNSCC cell lines, DNMT3b was upregulated, while E-cadherin was downregulated, suggesting that DNMT3B may be involved in induction of epithelial-mesenchymal transition (EMT). Moreover, miR-29b mimic leads to a decrease of DNMT3b expression and inhibits EMT (Chen et al. 2016b). DNMTs expression may be associated with the expression of other epigenetic factors. Mochizuki et al. (2018) observed that overexpression of EZH2, member of Polycomb protein, is positively correlated with the upregulation of $D N M T 3 a$ but not associated with DNMT3b in HNSCC. The level of enzyme may be also modulated by a dietary 
component such as folate (diet-derived methyl donor). Methyl donor depletion leads to increased expression of DNMT3a in HPV(+) HNSCC cell line, while DNMT1 and DNMT3a expressions are either not altered or not significantly higher, respectively (Hearnden et al. 2018). DNMTs may be a potential target for enhancement of HNSCC chemotherapy by the use of inhibitors of DNMTs and reversal of genes methylation (Suzuki et al. 2009). It has been reported that DNMT1 was a target of miR-148a-3p in LSCC. It was found that the overexpression of miR-148a-3p downregulated DNMT1 expression, which led to upregulation of RUNX3, tumor suppressor, through decreasing its methylation (Jili et al. 2016).

\section{TET}

Ten-eleven translocation (TET) family of enzymes are pivotal factors of epigenetic regulation machinery through demethylation process. This family of 5-mC hydroxylases is composed of TET-1, TET-2, and TET-3 proteins, which catalyze the conversion of 5-methylcytosine to 5-hydroxymethylcytosine (Tahiliani et al. 2009). TET proteins are large enzymes of 180-230-kDa (Rasmussen and Helin 2016) and have a C-terminal catalytic domain with TET-1 and TET-3 containing also N-terminal CXXC zinc finger domain (Zhao and Chen 2013). TET proteins are involved in many important processes during mammalian development such as embryonic development, but also may influence tumorigenesis (Tan and Shi 2012). The lower expression of TET proteins occurs in malignant and solid tumors (Rasmussen and Helin 2016). During tumorigenesis, the TET activity is reduced by tumor hypoxia. Hypoxia influences increased promoter methylation and leads to decreased activity of TET enzymes in many tumors, also in HNSCC (Thienpont et al. 2016). Also, methyl donor depletion may influence expression of TET-1, what was confirmed by Hearnden et al. (2018). They showed that reduced methyl donor was associated with increased expression of TET-1 in HPV-positive HNSCC cell line.

The aberrantly methylated TET enzymes in HNSCC patients were studied by Misawa et al. (2018a), who reported lower expression of TET-1 and TET-3 in HNSCC, while methylation level of these genes was higher in cancer cells, suggesting that downregulation of TET-1 and TET-3 must have been associated with their promoter methylation. Moreover, the multivariate analysis revealed that TET-3 methylation in OSCC and oropharyngeal cancer was connected with poor survival of HNSCC patients (Misawa et al. 2018a).

Decreased expression of TET-1 gene occurs also in laryngeal squamous cell carcinoma (LSCC) and is connected with a lower level of 5-hmC, suggesting that the level of 5-hmC is strongly correlated with the level of TET-1 and may be a poor prognostic factor of LSCC patients in an early stage of cancer (Zhang et al. 2016). However, Zhang et al. (2016) did not find any significant differences in the expression of TET-2 and TET-3 between LSCCs and normal tissues. On the other hand, downregulation of TET-2 was correlated with a lower level of 5-hmC in OSCC patients (Jäwert et al. 2013). Wang et al. (2017) observed that the expression of 5-hmC was significantly reduced in oral cancer and the expression of TET-2 was significantly lower in OSCC patients, which may be contributing to cancer development. Moreover, increased level of 5-hmC was correlated 
with decreased overall survival, suggesting its usability as a prognostic factor for OSCC (Wang et al. 2017). TET enzyme may influence a response to chemotherapy in HNSCC. Song et al. (2019) observed that TET-2 promoted 5-hmC formation after the administration of chemotherapeutic agents like doxorubicin. Moreover, PML (promyelocytic leukemia) recruited TET-2 to regulate DNA modification during chemotherapy of HNSCC, and as a result impaired cell proliferation. Furthermore, higher levels of TET and PML were associated with better overall survival of HNSCC patients (Song et al. 2018). Wang et al. (2018b) showed that a decreased expression of TET-1 in OSCC may lead to increased promoter methylation of MGMT, and enhanced the sensitivity of OSCC stem cells to chemotherapeutics like cisplatin.

\section{Histone Modifications}

Histone modifications play a key role in regulating chromatin structure and DNA transcriptional activity, and aberrations in histone modification are associated with cancer (Bannister and Kouzarides 2011).

A nucleosome, the primary unit of chromatin, is composed of four histone proteins (two copies of $\mathrm{H} 2 \mathrm{~A}, \mathrm{H} 2 \mathrm{~B}, \mathrm{H} 3$, and H4) which make a histone octamer, and 147 base pairs of DNA wrapped around it (Hatziapostolou and Iliopoulos 2011; Osorio and Castillo 2016). Histones are basic proteins which consist of a globular C-terminal domain and N-terminal tails. The tails undergo many different posttranslational modifications (PTMs) including acetylation, methylation, phosphorylation, ubiquitination, and ADP-ribosylation (Park et al. 2011; Hatziapostolou and Iliopoulos 2011) which modulate interactions between DNA and the histone octamer and in consequence the accessibility of the DNA (Bowman and Poirier 2015). PTMs are carried out by enzymes that add or remove the chemical group on the amino acids arginine, serine, or lysine (Fig. 3) (Hatziapostolou and Iliopoulos 2011; Bowman and Poirier 2015; Castilho et al. 2017).

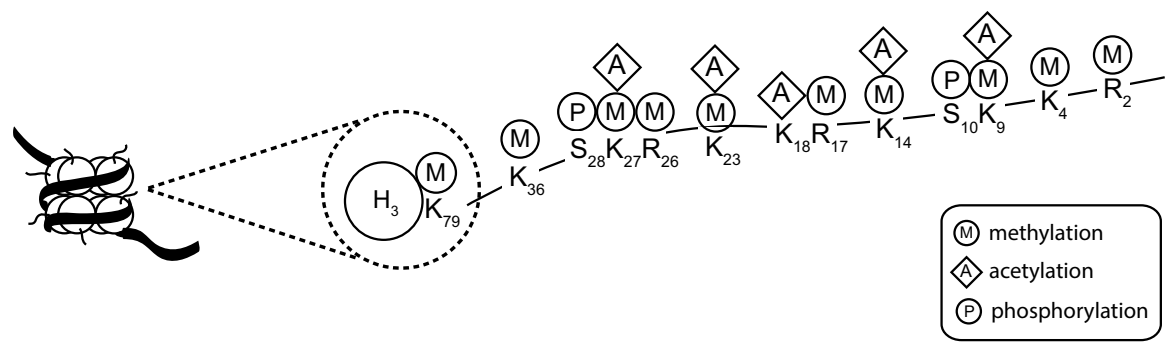

Fig. 3 Posttranslational modifications of histones (updated from Bannister and Kouzarides 2011; Osorio and Castillo 2016) 


\section{Histone Acetylation}

Acetylation and deacetylation influence the conformation of nucleosomes and are catalyzed by histone acetyltransferases (HATs) and histone deacetylases (HDACs), respectively. Lysine acetylation results in relaxation of the chromatin structure, facilitating gene transcription (Momparler 2003; Castilho et al. 2017), while deacetylation silences genes by decreasing the accessibility of DNA to transcription factors (Momparler 2003). Deregulation of histone acetylation may cause increased transcription of various genes, and in consequence can lead to malignant transformation (Mancuso et al. 2009; Webber et al. 2017). Giudice et al. (2013) showed that in HNSCC cells, chromatin hypoacetylation occurs, which is evidenced by low level of histone $\mathrm{H} 3$ acetylated on lysine 9 (H3K9) in comparison to normal oral keratinocytes. In HNSCC patients, the level (expression) of histone $\mathrm{H} 4$ acetylated on lysine 16 (H4K16ac) is connected with early clinical stages of cancer, whereas histone H3 acetylated on lysine $9(\mathrm{H} 3 \mathrm{~K} 9 \mathrm{ac})$ is connected not only with the early clinical stages but also with increasing levels of differentiation and absence of lymph nodes (Noguchi et al. 2013). OSCC patients have hypoacetylated H3K9ac, and in addition this modification of chromatin condensation is connected with lower survival rate (Webber et al. 2017). Moreover, histone H3 acetylated on lysine 27 (H3K27ac) at the promoter of lncRNA PLAC2 leads to upregulation of PLAC2, and in results influences on OSCC progression via activating Wnt/ $\beta$-catenin signaling pathway (Chen et al. 2019). A connection between tumor progression and histone acetylation was also found by Chen et al. (2013c), who showed that high expression of H3K18ac and a low level of $\mathrm{H} 3 \mathrm{~K} 4 \mathrm{a}$ were associated with an advanced stage and a $\mathrm{T}$ status of oral cancer, while $\mathrm{H} 3 \mathrm{~K} 4$ as additionally was associated with nodal invasion and poor survival. The level of expression of histone deacetylases has an influence on tumor progression; for instance, the overexpression of HDAC9 stimulates the development of OSCC by alterations of the cell cycle, cell proliferation, and apoptosis (Rastogi et al. 2016). These studies show that in oral cancer cases, the overexpression of HDAC2 is frequent and univariate analysis shows that higher HDAC2 expression is associated with shorter overall survival, suggesting that its level can be a useful prognostic marker for patients with oral cancer (Chang et al. 2009). Furthermore, in OSCC, increased expressions of mRNA and HDAC6 protein are detected. Interestingly, HDAC6 expression is associated with tumor aggressiveness (Sakuma et al. 2006). Almeida et al. (2014) found that HDAC inhibitors effectively protect against cisplatin resistance caused by $\mathrm{NF \kappa B}$ signaling, which affects tumor resistance by histone deacetylation. Moreover, chemical inhibition of histone deacetylase classes I and II impairs HNSCC proliferation and decreases the fraction of cancer stem cells (Giudice et al. 2013; Castilho et al. 2017).

\section{Histone Methylation}

Methylation of lysine, histidine, and arginine in histones is involved in changes of the chromatin structure and gene regulation but without altering the charge of histones. The methyl group is added to amino acid residues by histone methylases 
(HMT) while histone demethylases reverse this process. Lysine may occur in the mono-, di-, or tri-methylated form (Bannister and Kouzarides 2011; Castilho et al. 2017). The epigenetic effects of methylation depend on the location where the methyl group is added. Histone $\mathrm{H} 3$ has a few different lysine sites for methylation like K4, K9, K27, K36, or K79. An open chromatin structure results from methylation of $\mathrm{H} 3 \mathrm{~K} 4$, in contrast to methylation of $\mathrm{H} 3 \mathrm{~K} 9$ that causes the condensation of chromatin (Lachner and Jenuwein 2002; Momparler 2003; Le et al. 2014). Furthermore, histone methylation is a marker for both transcriptionally active (H3K4me3, $\mathrm{H} 3 \mathrm{~K} 79 \mathrm{me} 3$ or H3K36me3) or silenced (H3K9me2, H3K9me3 or H3K27me3) genes (Bedi et al. 2014; Castilho et al. 2017). In OSCCC, a high level of H3K27me3 is associated with tumor progression (advanced $\mathrm{T}$ and $\mathrm{N}$ status, and stage of tumor), and also with disease-free survival as well as cancer-specific survival (Chen et al. 2013c). Furthermore, the level of H3K4me3 is decreased, whereas that of H3K4me 2 is higher in OSCCC cases (Mancuso et al. 2009).

Histone modifications are also associated with the Polycomb protein complex which plays a key role in chromatin remodeling and transcription regulation (Sauvageau and Sauvageau 2010). One member of the Polycomb group is EZH2 (enhancer of zeste homologue 2) which regulates gene silencing by methylation at $\mathrm{H} 3 \mathrm{~K} 27$, whose expression is upregulated in OSCCC cell lines in comparison to cells from dysplasia or normal mucosae. In addition, overexpression is associated with clinical stage and tumor size and negatively correlated with the histological differentiation, leading Kidani et al. (2009) to suggest that the overexpression of that methyltransferase may be used as a prognostic marker for OSCC patients. On the other hand, EZH2 is overexpressed in HNSCC cell lines although this is not associated with an aberrant H3K27me3 status. Gannon et al. (2013) reported that inhibition of EZH2 may decrease the methylation level of H3K27 and in consequences may stimulate expression of differentiation genes in differentiation-refractory HNSCC cell lines. Additionally, higher expression of EZH2 mRNA was confirmed in HNSCC patients and is correlated with overexpression of DNMT3A, as well as with stage of cancer and recurrence, which suggests a role of EZH2 in tumor progression (Mochizuki et al. 2018). In OSCC, Chen et al. (2013b) found overexpression of methyltransferases for $\mathrm{H} 3 \mathrm{~K} 9$ and $\mathrm{H} 3 \mathrm{~K} 27$ (SUV39H1 and $\mathrm{EZH} 2$, respectively), which has consequences for prognostics; methyltransferase for $\mathrm{H} 3 \mathrm{~K} 9$ is associated with advanced tumor stage, while higher expression of EZH2 is positively correlated with LN metastasis. In TSCC cell lines and TSCC patient samples, mRNA for another member of the Polycomb complex, Bmil (B lymphoma Mo-MLV insertion region 1 homolog), is upregulated and associated with shorter survival, suggesting the possible use of Bmil expression as a prognostic marker ( $\mathrm{Li}$ et al. 2014c).

\section{Histone Phosphorylation}

Phosphorylation by adding a phosphate group from ATP is a modification occurring primarily on threonine, serine, and tyrosine located in $\mathrm{N}$-terminal histone tails and is regulated by kinases and phosphatases. As a consequence, the histones have a lower positive charge which may influence chromatin organization (Bannister and 
Kouzarides 2011). The threonine protein kinase of H3S10 (ARK2) is overexpressed in oral cancer cases in the Taiwanese population and this upregulation in nuclei is connected with poor survival, while the cytosolic overexpression is correlated with the T status and stage of cancer. ARK2 may therefore be useful as a prognostic biomarker (Chen et al. 2013b). Furthermore, the overexpression of ARK2 in HNSCC patients was confirmed by Qi et al. (2007), who reported that higher expression of that enzyme is correlated with histological differentiation, cell proliferation, and metastasis in oral cancer, which indicates a role in OSCC progression.

\section{Histone Sumoylation}

Sumoylation is a modification similar to ubiquitination in which three enzymes, E1, $\mathrm{E} 2$, and E3, add molecules of the small ubiquitin-like modifier (SUMO) to histone lysines (Bannister and Kouzarides 2011). There are also sumo-specific proteases (SENPs) which can reverse sumoylation, seven of which are known in humans (Ding et al. 2008). One of these is SNEP5, whose expression level has been reported to be higher in oral cancer specimens compared to normal epithelia, suggesting that SNEP5 expression is associated with differentiation of OSCC (Ding et al. 2008). On the other hand, Katayama et al. (2007) found that SUMO-1 is overexpressed in human OSCC cell lines and OSCC tissues from patients, and might be connected with tumor cell proliferation.

\section{Non-coding RNAs}

One of the epigenetic mechanisms is regulation of non-coding RNAs (ncRNAs), which play important role in cellular homeostasis, development, and differentiation, as well as it may cause disease development, including cancer (Wang and Chang 2011; Esteller and Pandolfi 2017). ncRNAs are not translated into proteins and may be divided into classes based on their transcript size: small ncRNAs (including miRNAs, siRNAs, and piRNAs) and long ncRNAs (lncRNAs) such as long intergenic ncRNAs, circular RNAs, and pseudogene transcripts (Wang and Chang 2011; Osorio and Castillo 2016; Esteller and Pandolfi 2017; Wei et al. 2017). Below we will present some miRNAs and lncRNAs associated with HNSCC.

\section{miRNAs}

MicroRNAs (miRNAs), one of the classes of small non-coding RNA, are short (17-25 nucleotides) single-stranded RNAs that are partially complementary to the 3 '-untranslated region of messenger RNAs. Through binding to mRNAs they cause their degradation or inhibit their translation, and as a result they modulate expression of nearly 30\% of human genes (Lee and Dutta 2009; Shiiba et al. 2010; Osorio and Castillo 2016). miRNAs participate in many cellular processes like proliferation, differentiation, development, and apoptosis (Bartel 2004; Kimura et al. 2010; Osorio and Castillo 2016). Furthermore, miRNAs may be classified as oncogenes or 
suppressor genes based on their cancer-related expression. A subgroup of miRNAs, epi-miRNAs, is associated with epigenetic factors like HDACs or DNMTs, suggesting that they may affect members of the epigenetic machinery and in consequence may influence gene expression. The level of miRNA expression is deregulated in cancer initiation and progression (Hatziapostolou and Iliopoulos 2011; Castilho et al. 2017) and recent studies find that miRNAs may be used as biomarkers for cancers (Shiiba et al. 2010; Irani 2016). Recent results concerning associations between miRNAs and HNSCC are presented below.

\section{Oncogenic miRNAs}

One of the best-known oncogenic miRNAs is miR-21, which has many targets genes of which most are suppressor genes like PTEN, TPM1, TIMP3, and PDCD4 (Li et al. 2009; Selcuklu et al. 2009; Scapoli et al. 2010), suggesting that miR-21 plays a role in cancer invasion and metastasis (Zhu et al. 2008). In HNSCC, most of the target genes for miR-21 are tumor suppressors (Chen et al. 2013a), and meta-analysis shows that in HNSCC miR-21 is upregulated (Chen et al. 2012; Kumarasamy et al. 2019). Overexpression of miR-21 is associated with decreased 5-year survival in HNSCC patients (Avissar et al. 2009b). Li et al. (2009) revealed that overexpression of miR-21 is negatively correlated with expression of PTEN and TPM1, as well as associated with advanced clinical stage of TSCC, LN metastasis, and poor differentiation, suggesting that miR-21 may be a useful prognostic marker for patients with tongue cancer. Singh et al. (2018) observed that expression of mir-21 is significantly positively correlated with clinical stages I-IV of oral cancer.

miR-155-5p is another well-known oncogenic miRNA. In OSCC patients with metastasis to neck lymph nodes this miRNA is overexpressed, and is therefore suggested to be a poor prognostic factor, but also may be used as a novel target in oral cancer therapy (Baba et al. 2016). Overexpression of miR-155-5p was associated with TMN stage, LN metastasis, and poor differentiation also in LSCC (Cui et al. 2019). On the other hand, Rather et al. (2013) found that miR-155 targets CDC73, which is a tumor suppressor gene. In OSCC patients, overexpression of miR-155 decreases expression of $C D C 73$ and in consequence promotes cell proliferation as well as inhibiting apoptosis. It has been proposed that miR-155 plays an important role in regulation of cell growth through its target genes CDC73 (Rather et al. 2013) and SOX10 (Cui et al. 2019), although it is upregulated in nasopharyngeal cancer (Chen et al. 2009).

miR-93 is overexpressed in HNSCC tissues and cell lines. Overexpression is associated with clinical stage, tumor progression, and LN metastasis, as well as inversely correlated with poor overall survival, suggesting that miR-93 might be an important factor in the progression of head and neck cancer (Li et al. 2015).

miR-211 has been recognized as targeting transforming growth factor- $\beta$ type II receptor $(T G F \beta R I I)$ and thus promoting tumor progression. In HNSCC samples with metastasis, the expression of miR-211 is negatively correlated with expression of TGF $\beta$ R2 protein, and in consequence is associated with poor prognosis for HNSCC patients (Chu et al. 2013). Zheng et al. (2018) also reported overexpression of miR211 in tissues and cell lines from oral cancer, and interestingly found that higher 
miRNA expression is correlated with decreased expression of the tumor suppressor gene BIN1 (bridging integrator-1) which may be a target of miR-211. Overexpression of BIN1 protein in OSCC cell lines is associated with decreased proliferation and migration, suggesting that miR-211 may be a new target in treatment of oral cancer.

Overexpression of miR-134 occurs in HNSCC patients, and high expression is connected with nodal metastasis and poor survival (Liu et al. 2014). Although miR134 is upregulated in OSCC cell lines, its potential target gene PDCD7 has a lower expression, an effect enhancing OSCC progression (Peng et al. 2018).

miR-205-5p is overexpressed in tumoral and peritumoral HNSCC tissues, and targets $R A D 17$ and $B R C A 1$, DNA repair genes. Lower expression of RAD17 and $B R C A 1$ may increase defects in DNA damage response and cause chromosomal instability (Valenti et al. 2019).

miR-31 is another oncogenic miRNA for HNSCC and is overexpressed in tissues and serum from HNSCC patients; furthermore an increased level is associated with TNM status and node stage. In addition, upregulation of miR-31 is connected with poor prognosis for HNSCC patients, suggesting its use as a prognostic marker (Wang et al. 2018a). miR-31 down-regulates the tumor suppressor gene ARID1A (AT-rich interacting domain) and decreases expression of ARID1A protein, a member of the chromatin remodeling SWI/SNF complex, and may inhibit stemness and oncogenicity. HNSCC patients with increased miR-31 and decreased ARID1A expression have poor survival (Lu et al. 2016). However, miR-31 is downregulated in laryngeal cancer cases and a low level of expression is associated with an advanced stage of cancer (Yang et al. 2018).

\section{Tumor Suppressor miRNAs}

Recent studies show that HNSCC patients have a low expression of miR-9. Moreover, in HNSCC cell lines, knockdown of miR-9 causes an increased invasiveness, cell cycle progression, cellular proliferation, and colony formation, and targets the gene CXCR4, a discovery which may be useful in therapy (Hersi et al. 2018). In NPC patients mir-9-3p is down-regulated, while its targets genes fibronectin 1 $(F N 1), \beta 1$ integrin $(I T G B 1)$, and $\alpha 5$ integrin $(I T G A V)$ are upregulated. On the other hand, in NPC cell lines, higher expression of miR-9-3p decreases the proliferation, invasion, and migration of nasopharyngeal cancer cells (Ding et al. 2017).

Downregulation of miR-16 expression is observed in OSCC patients and cancer cell lines and its lower expression is negatively correlated with overexpression of its target gene Tousled-like kinase 1 (TLK1) and associated with positive LN metastasis, as well as with higher TNM stage and poor prognosis (Hu et al. 2018a). Other targets genes for miR-16, the oncogenes $A K T 3$ and $B C L 2 L 2$, may promote cell proliferation and inhibit apoptosis in OSCC cells; oral cancer cell lines show a negative correlation between expression of miR-16 and expression of AKT3 and BCL2L2, confirming a tumor-suppressing role of miR-16 in oral cancer (Wang and Li 2018).

A bioinformatics-based study showed that miR-99a-5p is downregulated in HNSCC and is negatively associated with expression of PIK3CD (phosphatidylinositol-4,5-bisphosphate 3-kinase catalytic subunit delta), which takes part in the 
PI3K-Akt signaling pathway, suggesting that it may be a tumor suppressor in head and neck cancer (Chen et al. 2018). miR-99a is also down-regulated in oral cancer and cell lines, but lower expression is not connected with the clinical stage; moreover, decreased expression of miR-99a promotes migration, proliferation, and cell invasion which are connected with higher expression of the MTMR3 gene, a miR-99a target (Kuo et al. 2014). Yan et al. (2012) confirmed decreased expression of miR-99a in patients with oral cancer, and studies of TSCC cell lines show that higher expression of miR-99a inhibits cell growth and starts apoptosis. The mTOR gene (mammalian target of rapamycin), a serine/threonine protein kinase which plays an important role in regulating many pathways such as cell growth, cell survival, and differentiation is a potential target of miR- 99a (Watanabe et al. 2011; Yan et al. 2012). Wei et al. (2019) also reported reduced expression of miR99a-3p among HNSCC patients.

miR-34a is downregulated in HNSCC and reduced expression is characteristic for samples with LN metastasis; its target gene AREG (ligand of epidermal growth factor) takes part in tumor development, suggesting that miR-34a may play a key role in the suppression of invasion and metastasis in HNSCC (Zhang et al. 2015a). Other studies also observed downregulation of miR-34a (Scapoli et al. 2010; Kumar et al. 2012), and miR-34a expression is low in HNSCC cell lines (Kumar et al. 2012). Ectopic expression of miR-34a using in vitro and in vivo models caused inhibition of cell migration and proliferation of HNSCC cell lines. Moreover, miR-34a regulates tumor angiogenesis in head and neck cancer (Kumar et al. 2012).

Downregulation of miR-638 occurs in OSCC and is negatively correlated with TMN stages and LN metastasis. Besides, Tang et al. (2019) reported that restored expression of miR-638 inhibited migration, invasion, and proliferation of OSCC cells, and suggested that miR-638 might be a tumor suppressor by miR-638/wnt/ b-catenin axis.

miR-375 is downregulated nearly 22-fold in HNSCC tissues compared to normal tissues (Avissar et al. 2009a), suggesting that it may play a role in the transcriptional repression of an oncogene. Additionally, the expression ratio of miR-221 to miR-375 may serve as a cancer prognostic tool due to its high specific and sensitivity.

miR-625 may be a tumor suppressor miRNAs, because its level is lower in laryngeal squamous cell carcinoma (LSCC) and low expression is correlated with an advanced clinical stage of cancer and LN metastasis (Li et al. 2019b). On the other hand, miR-625 could be used in therapy because its overexpression decreases the invasion, proliferation, and migration of LSCC cells by targeting the gene SOX4.

Other studies and meta-analyses show that in HNSCC patients some miRNAs are upregulated, such as miR-126 and miR-223 in OSCC (Tachibana et al. 2016), miR-196b (Luo et al. 2019), miR-31 (Kao et al. 2019), miR-1275 in HNSCC (Liu et al. 2018), miR-212 and miR-129 in OSCC (Scapoli et al. 2010), and miR-130b in HNSCC (Chen et al. 2012), while others are down-regulated, such as miR-145-5p in LSCC (Gao et al. 2019), miR-29a in OSCC (Huang et al. 2019), miR-200b in HNSCC (Kumarasamy et al. 2019), miR-125a-5p in HNSCC (Vo et al. 2019), miR486-3p and miR-337-3p in OSCC (Chou et al. 2019), miR-224 in OSCC (Lu et al. 2019), miR-135b, miR-197, miR-378, miR224, and miR-34a in OSCC (Scapoli et al. 2010), miR-100 and miR-375 in HNSCC (Chen et al. 2012). 


\section{IncRNAs}

lncRNAs are transcribed RNA molecules, which have a length of more than 200 nucleotides, do not encode proteins, and participate in positive and negative regulation of gene expression in the transcriptional, as well as the post-transcriptional level (Wang and Chang 2011; Chen 2016; Wei et al. 2017). Moreover, they regulate the transcription via modulation of chromatin structure and in consequence, are pivotal regulators of diverse biological processes, such as apoptosis, cell proliferation, metabolism, cell cycle, etc. (Akhade et al. 2017). lncRNAs may contribute to cancer development as oncogenes or tumor suppressors (Momen-Heravi and Bala 2018), thus might be used as biomarkers in diagnostics and target in therapy (Yang and Deng 2014).

An example of lncRNA associated with HNSCC development is HOXA11 antisense RNA (HOXA11-AS), which was found to be overexpressed in LSCC (Qu et al. 2018) and OSCC (Li et al. 2019a; Wang et al. 2019b). Upregulation of HOXA11-AS is significantly associated with poor prognosis of LSCC patients, while downregulation in LSCC cell lines is connected with inhibition of the invasion and migration of cancer cells, suggesting an oncogenic role of HOXA11-AS (Qu et al. 2018). Similarly, Li et al. (2019a) observed that higher expression detected in OSCC patients was correlated with lymph node metastasis, grade and clinical stage of oral cancer, while in OSCC cells in vitro it promoted proliferation. Moreover, bioinformatic analysis suggested that miR-518a-3p may be a target of HOXA11-AS, and in consequence a promoter of PDK1 expression in OSCC (Li et al. 2019a). On the other hand, Wang et al. (2019b) revealed another target of HOXA11-AS, miR-214-3p, which negatively regulated the proto-oncogene PIM1. Importantly, HOXA11-AS/ miR-214-3p/PIM1 axis may be a potential target for oral cancer chemotherapy improvement. lncRNA RHPN1-ASl acts as an oncogene, which was confirmed by Qiu et al. (2019), who showed that RHPNI-ASI had a higher expression in HNSCC patients. Its knockdown was associated with significant inhibition of migration and invasion of HNSCC cell lines. Moreover, downregulation of RHPN1-AS1 promoted apoptosis of cancer cells. In oral cancer, Guo et al. (2018) reported that lncRNA CEBPA-AS1 was upregulated in OSCC tissues and Tca8113 and Cal27 cell lines, suggesting that IncRNA CEBPA-AS1 may promote OSCC development. Moreover, the increased expression correlated with lymph node metastasis, poor differentiation, and high clinical stage of OSCC. The results indicated that lncRNA CEBPAAS1 might be a novel prognostic biomarker and therapeutic target for patients with oral cancer. The lncRNA ST7-AS1 is the antisense transcript for ST7 (suppressor of tumorigenicity 7 protein) and plays an oncogenic role in LSCC. The ST7-AS1 overexpression in LSCC tissues and cell lines is associated with poor overall survival of LSCC patients. Qin et al. (2019) showed that interacting partner for ST7-AS1 was CARM1, which promoted metastasis and cancer development throughout its methyltransferase activity. In results, they showed a novel ST7-AS1/CARM1/Sox-2 signaling axis occurring in LSCC progression. IncRNAs may also inhibit HNSCC development, such as lncRNA LINC01133, which is downregulated in OSCC. However, the increased expression is associated with decreased metastasis and longer survival of OSCC patients, suggesting that LINC01133 may play a role of tumor suppressor 
gene (Kong et al. 2018). Downregulation of lncRNA AC026166.2-001 occurs in LSCC patients. Shen et al. (2018) reported that higher expression of AC026166.2001 suppressed cell proliferation and migration in LSCC cells, inhibited cells cycle, and supported cell apoptosis in laryngeal cancer. Also other lncRNAs are upregulated in HNSCC and may display oncogenic properties, such as ZFAS1 (Kolenda et al. 2019), PVT1 (Yu et al. 2018), CASC9 (Sassenberg et al. 2019), TUG1 (Zhang et al. 2018b), MIAT (Zhong et al. 2019), SNHG20 (Wu et al. 2019), or RGMB-AS (Xu and Xi 2019), or downregulated and may act as tumor suppressor genes, such as STR5-AS (Wang et al. 2019a), C5orf66-AS1 (Lu et al. 2018), AC012456.4 (Hu et al. 2018b), LINC01133 (Kong et al. 2018), ZNF667, and ZNF667-AS1 (Meng et al. 2019).

\section{Chromatin Remodeling}

Chromatin remodeling describes the dynamic changes of chromatin organization which influence regulation of gene transcription, replication of DNA, apoptosis, DNA repair, and also chromosome condensation and segregation (Wang et al. 2007a). Chromatin remodeling is undertaken by mechanism such as covalent histone modifications and DNA methylation which were described above, and also uses histone variants and ATP-dependent complexes of chromatin remodeling enzymes. Deregulation of chromatin remodeling may contribute to many diseases, including cancer (Wang et al. 2007b). ATP-dependent enzymes engaged in chromatin remodeling play important roles in regulation of gene transcription by modifying the organization of nucleosomes (Hatziapostolou and Iliopoulos 2011). Importantly, to remodel nucleosome organization, these ATPases utilize the energy from ATP hydrolysis. Chromatin remodeling ATPases are composed of four families, SWI/SNF, ISWI, NuRD/Mi-2/CHD, and INO80 (Bao and Shen 2007; Wang et al. 2007b). The SWI/SNF (switching/sucrose nonfermenting) family consists of two subfamilies, PBAF (polybromo-associated factor) and BAF (BRG1 or BRMassociated factor) (Halliday et al. 2009). SWI/SNF is essential in regulation of transcription, repair, recombination, and cell cycle progression as well as in the immune pathway and organ development, and in consequence nonfunctional complexes may influence carcinogenesis (Bao and Shen 2007; Halliday et al. 2009). The SWI/SNF complex also contains bromodomain units (Halliday et al. 2009). BRD7 (bromodomain-containing protein 7), a subunit of the PBAF complex, is hypermethylated in $74 \%$ of OSCC cases examined (Balasubramanian et al. 2015). Immunoreactivity of BAF250a, another subunit of SWI/SNF, is reduced to various levels in invasive OSCC cells compared to normal oral epithelial cells and is connected with poor outcome in OSCC patients with early pathological T-stage (T1/T2) without lymph node metastasis. However, no association is found between lower BAF250a immunoreactivity and smoking or alcohol abuse, gender, age, or LN metastasis (Inoue et al. 2018).

RSF1 is one subunit of ISWI remodeling factors, and its expression is upregulated in OSCC. Moreover, higher expression is correlated with poor overall survival 
in patients with oral cancer and is also associated with LN metastasis, as well as with advanced clinical stage of tumor and recurrent disease (Fang et al. 2011).

The Mi-2/NuRD (Nucleosome Remodeling Deacetylase) complex is also an important complex for chromatin remodeling. One of its subunits is DOC1 (Deleted in Oral Cancer 1) (Bao and Shen 2007; Wang et al. 2007b) whose loss is connected with OSCC; in OSCC cell lines, re-expression of DOC1 decreases cell proliferation or migration and induces a mesenchymal-epithelial transition (Mohd-Sarip et al. 2017).

The chromatin remodeling complex INO80 is also required for correct regulation of transcription and organization of nucleosomes, and incorrect function of its subunits may influence carcinogenesis (Bao and Shen 2007; Wang et al. 2007b).

\section{Conclusions}

Recent studies show clearly that epigenetic mechanisms play important roles in head and neck carcinogenesis. Aberrant methylation of repeat sequences like LINE1 or tumor suppressors such as DAPK, RASSF1 and, ECAD is undoubtedly crucial in tumor progression. Moreover, epigenetic alteration connected with histone modification and chromatin remodeling may cause open chromatin structure and facilitate transcriptions of factors involved in human malignancies. Also expression of microRNAs may influence tumor progression and in consequence the prognosis for patients. On the other hand, knowledge about dysregulated microRNAs and their target genes may improve therapeutic strategies. Importantly, utilizing information about hypo- or hypermethylation markers may be useful and reliable for early detection and prognosis. Because epigenetic changes are reversible, further research about aberrant patterns of epigenetic events is important to provide better and more effective therapies for patients with head and neck cancer.

Acknowledgements The authors would like to thank Aleksandra Bibrzycka for her help in creating the figures.

\section{Compliance with Ethical Standards}

Conflict of interest The authors declare that they have no conflict of interest.

Open Access This article is distributed under the terms of the Creative Commons Attribution 4.0 International License (http://creativecommons.org/licenses/by/4.0/), which permits unrestricted use, distribution, and reproduction in any medium, provided you give appropriate credit to the original author(s) and the source, provide a link to the Creative Commons license, and indicate if changes were made. 


\section{References}

Adhikari BR, Uehara O, Matsuoka H et al (2017) Immunohistochemical evaluation of Klotho and DNA methyltransferase 3a in oral squamous cell carcinomas. Med Mol Morphol 50:155-160. https://doi. org/10.1007/s00795-017-0156-9

Akhade VS, Pal D, Kanduri C (2017) Long noncoding RNA: genome organization and mechanism of action. Adv Exp Med Biol 1008:47-74. https://doi.org/10.1007/978-981-10-5203-3_2

Allameh A, Moazeni-Roodi A, Harirchi I et al (2018) Promoter DNA methylation and mRNA expression level of p16 gene in oral squamous cell carcinoma: correlation with clinicopathological characteristics. Pathol Oncol Res 25(4):1535-1543. https://doi.org/10.1007/s12253-018-0542-1

Almeida LO, Abrahao AC, Rosselli-Murai LK et al (2014) NFkB mediates cisplatin resistance through histone modifications in head and neck squamous cell carcinoma (HNSCC). FEBS Open Bio 4:96104. https://doi.org/10.1016/j.fob.2013.12.003

Alsofyani AA, Alsiary RA, Samkari A et al (2017) Prognostic potential of KLOTHO and SFRP1 promoter methylation in head and neck squamous cell carcinoma. J Appl Genet 58:459-465. https:// doi.org/10.1007/s13353-017-0404-7

Alyasiri NS, Ali A, Kazim Z et al (2013) Aberrant promoter methylation of PTEN gene among Indian patients with oral squamous cell carcinoma. Int J Biol Markers 28:298-302. https://doi. org/10.5301/JBM.5000030

Arantes LMRB, de Carvalho AC, Melendez ME et al (2014) Methylation as a biomarker for head and neck cancer. Oral Oncol 50:587-592. https://doi.org/10.1016/J.ORALONCOLOGY.2014.02.015

Arayataweegool A, Srisuttee R, Mahattanasakul P et al (2019) Head and neck squamous cell carcinoma drives long interspersed element-1 hypomethylation in the peripheral blood mononuclear cells. Oral Dis 25:64-72. https://doi.org/10.1111/odi.12944

Avissar M, Christensen BC, Kelsey KT, Marsit CJ (2009a) MicroRNA expression ratio is predictive of head and neck squamous cell carcinoma. Clin Cancer Res 15:2850-2855. https://doi. org/10.1158/1078-0432.CCR-08-3131

Avissar M, McClean MD, Kelsey KT, Marsit CJ (2009b) MicroRNA expression in head and neck cancer associates with alcohol consumption and survival. Carcinogenesis 30:2059-2063. https://doi. org/10.1093/carcin/bgp277

Baba O, Hasegawa S, Nagai H et al (2016) MicroRNA-155-5p is associated with oral squamous cell carcinoma metastasis and poor prognosis. J Oral Pathol Med 45:248-255. https://doi.org/10.1111/ jop. 12351

Balasubramanian A, Subramaniam R, Narayanan V et al (2015) BRD7 promoter hypermethylation as an indicator of well differentiated oral squamous cell carcinomas. Asian Pac J Cancer Prev 16:1615-1619

Bannister AJ, Kouzarides T (2011) Regulation of chromatin by histone modifications. Cell Res 21:381395. https://doi.org/10.1038/cr.2011.22

Bao Y, Shen X (2007) SnapShot: chromatin remodeling complexes. Cell 129:632.e1-632.e2. https://doi. org/10.1016/j.cell.2007.04.018

Bartel DP (2004) MicroRNAs: genomics, biogenesis, mechanism, and function. Cell 116:281-297. https ://doi.org/10.1016/S0092-8674(04)00045-5

Basu B, Chakraborty J, Chandra A et al (2017) Genome-wide DNA methylation profile identified a unique set of differentially methylated immune genes in oral squamous cell carcinoma patients in India. Clin Epigenetics 9:13. https://doi.org/10.1186/s13148-017-0314-X

Bedi U, Mishra VK, Wasilewski D et al. (2014) Epigenetic plasticity: a central regulator of epithelialto-mesenchymal transition in cancer. Oncotarget 5:2016-2029. https://doi.org/10.18632/oncotarget .1875

Bednarek K, Kostrzewska-Poczekaj M, Szaumkessel M et al (2018) Downregulation of CEACAM6 gene expression in laryngeal squamous cell carcinoma is an effect of DNA hypermethylation and correlates with disease progression. Am J Cancer Res 8:1249-1261

Bhat S, Kabekkodu SP, Jayaprakash C et al (2017) Gene promoter-associated CpG island hypermethylation in squamous cell carcinoma of the tongue. Virchows Arch 470:445-454. https://doi. org/10.1007/s00428-017-2094-2

Bowman GD, Poirier MG (2015) Post-translational modifications of histones that influence nucleosome dynamics. Chem Rev 115:2274-2295. https://doi.org/10.1021/cr500350x 
Byzia E, Soloch N, Bodnar M et al (2018) Recurrent transcriptional loss of the PCDH17 tumor suppressor in laryngeal squamous cell carcinoma is partially mediated by aberrant promoter DNA methylation. Mol Carcinog 57:878-885. https://doi.org/10.1002/mc.22808

Cai F, Xiao X, Niu X et al (2016) Aberrant methylation of MGMT promoter in HNSCC: a meta-analysis. PLoS ONE 11:e0163534. https://doi.org/10.1371/journal.pone.0163534

Cai F, Xiao X, Niu X, Zhong Y (2017) Association between promoter methylation of DAPK gene and HNSCC: a meta-analysis. PLoS ONE 12:e0173194. https://doi.org/10.1371/journal.pone.0173194

Castilho R, Squarize C, Almeida L (2017) Epigenetic modifications and head and neck cancer: Implications for tumor progression and resistance to therapy. Int J Mol Sci 18:1506. https://doi. org/10.3390/ijms 18071506

Chaisaingmongkol J, Popanda O, Warta R et al (2012) Epigenetic screen of human DNA repair genes identifies aberrant promoter methylation of NEIL1 in head and neck squamous cell carcinoma. Oncogene 31:5108-5116. https://doi.org/10.1038/onc.2011.660

Chang H-H, Chiang C-P, Hung H-C et al (2009) Histone deacetylase 2 expression predicts poorer prognosis in oral cancer patients. Oral Oncol 45:610-614. https://doi.org/10.1016/J.ORALO NCOLOGY.2008.08.011

Chen L-L (2016) Linking long noncoding RNA localization and function. Trends Biochem Sci 41:761-772. https://doi.org/10.1016/J.TIBS.2016.07.003

Chen H-C, Chen G-H, Chen Y-H et al (2009) MicroRNA deregulation and pathway alterations in nasopharyngeal carcinoma. Br J Cancer 100:1002-1011. https://doi.org/10.1038/sj.bjc.6604948

Chen Z, Jin Y, Yu D et al (2012) Down-regulation of the microRNA-99 family members in head and neck squamous cell carcinoma. Oral Oncol 48:686-691. https://doi.org/10.1016/j.oraloncolo gy.2012.02.020

Chen D, Cabay RJ, Jin Y et al (2013a) MicroRNA deregulations in head and neck squamous cell carcinomas. J oral Maxillofac Res 4:e2. https://doi.org/10.5037/jomr.2013.4102

Chen J-H, Yeh K-T, Yang Y-M et al (2013b) High expressions of histone methylation- and phosphorylation-related proteins are associated with prognosis of oral squamous cell carcinoma in male population of Taiwan. Med Oncol 30:513. https://doi.org/10.1007/s12032-013-0513-z

Chen Y-W, Kao S-Y, Wang H-J, Yang M-H (2013c) Histone modification patterns correlate with patient outcome in oral squamous cell carcinoma. Cancer 119:4259-4267. https://doi. org $/ 10.1002 /$ cncr.28356

Chen H-C, Yang C-M, Cheng J-T et al (2016a) Global DNA hypomethylation is associated with the development and poor prognosis of tongue squamous cell carcinoma. J Oral Pathol Med 45:409-417. https://doi.org/10.1111/jop.12381

Chen L-H, Hsu W-L, Tseng Y-J et al (2016b) Involvement of DNMT 3B promotes epithelial-mesenchymal transition and gene expression profile of invasive head and neck squamous cell carcinomas cell lines. BMC Cancer 16:431. https://doi.org/10.1186/s12885-016-2468-X

Chen Y, Yao J, Qin Y et al (2018) Biological role and clinical value of miR-99a-5p in head and neck squamous cell carcinoma (HNSCC): a bioinformatics-based study. FEBS Open Bio 8:12801298. https://doi.org/10.1002/2211-5463.12478

Chen F, Qi S, Zhang X et al (2019) lncRNA PLAC2 activated by H3K27 acetylation promotes cell proliferation and invasion via the activation of $\mathrm{Wnt} / \beta$-catenin pathway in oral squamous cell carcinoma. Int J Oncol 54:1183-1194. https://doi.org/10.3892/ijo.2019.4707

Chou S-T, Peng H-Y, Mo K-C et al (2019) MicroRNA-486-3p functions as a tumor suppressor in oral cancer by targeting DDR1. J Exp Clin Cancer Res 38:281. https://doi.org/10.1186/s1304 6-019-1283-z

Choudhury JH, Ghosh SK (2015) Promoter hypermethylation profiling identifies subtypes of head and neck cancer with distinct viral, environmental, genetic and survival characteristics. PLoS ONE. https://doi.org/10.1371/journal.pone.0129808

Chu T-H, Yang C-C, Liu C-J et al (2013) miR-211 promotes the progression of head and neck carcinomas by targeting TGFßRII. Cancer Lett 337:115-124. https://doi.org/10.1016/J.CANLE T.2013.05.032

Clausen MJAM, Melchers LJ, Mastik MF et al (2016) Identification and validation of WISP 1 as an epigenetic regulator of metastasis in oral squamous cell carcinoma. Genes Chromosomes Cancer 55:45-59. https://doi.org/10.1002/gcc.22310

Colacino JA, Dolinoy DC, Duffy SA et al (2013) Comprehensive analysis of DNA methylation in head and neck squamous cell carcinoma indicates differences by survival and clinicopathologic characteristics. PLoS ONE 8:e54742. https://doi.org/10.1371/journal.pone.0054742 
Cui W, Meng W, Zhao L et al (2019) TGF- $\beta$-induced long non-coding RNA MIR155HG promotes the progression and EMT of laryngeal squamous cell carcinoma by regulating the miR-155-5p/SOX10 axis. Int J Oncol 54:2005-2018. https://doi.org/10.3892/ijo.2019.4784

Degli Esposti D, Sklias A, Lima SC et al (2017) Unique DNA methylation signature in HPV-positive head and neck squamous cell carcinomas. Genome Med 9:33. https://doi.org/10.1186/s1307 3-017-0419-z

Demokan S, Dalay N (2011) Role of DNA methylation in head and neck cancer. Clin Epigenetics 2:123150. https://doi.org/10.1007/s13148-011-0045-3

Ding X, Sun J, Wang L et al (2008) Overexpression of SENP5 in oral squamous cell carcinoma and its association with differentiation. Oncol Rep 20:1041-1045

Ding Y, Pan Y, Liu S et al (2017) Elevation of MiR-9-3p suppresses the epithelial-mesenchymal transition of nasopharyngeal carcinoma cells via down-regulating FN1, ITGB1 and ITGAV. Cancer Biol Ther 18:414-424. https://doi.org/10.1080/15384047.2017.1323585

Domingos PLB, Souza MG, Guimarães TA et al (2017) Hypoxia reduces the E-cadherin expression and increases OSCC cell migration regardless of the E-cadherin methylation profile. Pathol Res Pract 213:496-501. https://doi.org/10.1016/J.PRP.2017.02.003

Don K, Ramani P, Ramshankar V et al (2014) Promoter hypermethylation patterns of P16, DAPK and MGMT in oral squamous cell carcinoma: a systematic review and meta-analysis. Indian J Dent Res 25:797. https://doi.org/10.4103/0970-9290.152208

Donninger H, Vos MD, Clark GJ (2007) The RASSF1A tumor suppressor. J Cell Sci 120:3163-3172. https://doi.org/10.1242/jcs.010389

Dvojakovska S, Popovic-Monevska D, Grcev A et al (2018) Promotor hypermethylated genes: prospective diagnostic biomarkers in oral cancerogenesis. J Craniomaxillofac Surg 46:1737-1740. https:// doi.org/10.1016/J.JCMS.2018.07.019

Ehrlich M (2009) DNA hypomethylation in cancer cells. Epigenomics 1:239-259. https://doi. org/10.2217/epi.09.33

Esteller M, Pandolfi PP (2017) The epitranscriptome of noncoding RNAs in cancer. Cancer Discov 7:359-368. https://doi.org/10.1158/2159-8290.CD-16-1292

Fang F-M, Li C-F, Huang H-Y et al (2011) Overexpression of a chromatin remodeling factor, RSF-1/ HBXAP, correlates with aggressive oral squamous cell carcinoma. Am J Pathol 178:2407-2415. https://doi.org/10.1016/J.AJPATH.2011.01.043

Foy J-P, Pickering CR, Papadimitrakopoulou VA et al (2015) New DNA methylation markers and global DNA hypomethylation are associated with oral cancer development. Cancer Prev Res (Phila) 8:1027-1035. https://doi.org/10.1158/1940-6207.CAPR-14-0179

Franzen A, Vogt TJ, Müller T et al. (2018) PD-L1 (CD274) and PD-L2 (PDCD1LG2) promoter methylation is associated with HPV infection and transcriptional repression in head and neck squamous cell carcinomas. Oncotarget 9:641-650. https://doi.org/10.18632/oncotarget.23080

Furlan C, Polesel J, Barzan L et al (2017) Prognostic significance of LINE-1 hypomethylation in oropharyngeal squamous cell carcinoma. Clin Epigenetics 9:58. https://doi.org/10.1186/s1314 8-017-0357-z

Ganci F, Sacconi A, Manciocco V et al (2012) Molecular genetics and biology of head and neck squamous cell carcinoma: Implications for diagnosis, prognosis and treatment. In: Agulnik M (ed) Head and neck cancer. InTech, Rijeka. https://doi.org/10.5772/31956.

Gannon OM, Merida de Long L, Endo-Munoz L et al (2013) Dysregulation of the repressive H3K27 trimethylation mark in head and neck squamous cell carcinoma contributes to dysregulated squamous differentiation. Clin Cancer Res 19:428-441. https://doi.org/10.1158/1078-0432.CCR-12-2505

Gao W, Zhang C, Li W et al (2019) Promoter methylation-regulated miR-145-5p inhibits laryngeal squamous cell carcinoma progression by targeting FSCN1. Mol Ther 27:365-379. https://doi. org/10.1016/J.YMTHE.2018.09.018

Ghantous Y, Schussel JL, Brait M (2018) Tobacco and alcohol-induced epigenetic changes in oral carcinoma. Curr Opin Oncol 30:152-158. https://doi.org/10.1097/CCO.0000000000000444

Giudice FS, Pinto DS, Nör JE et al (2013) Inhibition of histone deacetylase impacts cancer stem cells and induces epithelial-mesenchyme transition of head and neck cancer. PLoS ONE 8:e58672. https:// doi.org/10.1371/journal.pone.0058672

Gopisetty G, Ramachandran K, Singal R (2006) DNA methylation and apoptosis. Mol Immunol 43:1729_ 1740. https://doi.org/10.1016/J.MOLIMM.2005.11.010 
Guerrero-Preston R, Michailidi C, Marchionni L et al (2014) Key tumor suppressor genes inactivated by 'greater promoter' methylation and somatic mutations in head and neck cancer. Epigenetics. https ://doi.org/10.4161/epi.29025

Guo Y, Ma Y, Hu X et al (2018) Long non-coding RNA CEBPA-AS1 correlates with poor prognosis and promotes tumorigenesis via CEBPA/Bcl2 in oral squamous cell carcinoma. Cancer Biol Ther 19:205. https://doi.org/10.1080/15384047.2017.1416276

Halliday GM, Bock VL, Moloney FJ, Lyons JG (2009) SWI/SNF: A chromatin-remodelling complex with a role in carcinogenesis. Int J Biochem Cell Biol 41:725-728. https://doi.org/10.1016/J. BIOCEL.2008.04.026

Hatziapostolou M, Iliopoulos D (2011) Epigenetic aberrations during oncogenesis. Cell Mol Life Sci 68:1681-1702. https://doi.org/10.1007/s00018-010-0624-z

Hearnden V, Powers HJ, Elmogassabi A et al (2018) Methyl-donor depletion of head and neck cancer cells in vitro establishes a less aggressive tumour cell phenotype. Eur J Nutr 57:1321-1332. https:// doi.org/10.1007/s00394-017-1411-5

Herman JG, Baylin SB (2003) Gene silencing in cancer in association with promoter hypermethylation. N Engl J Med 349:2042-2054. https://doi.org/10.1056/NEJMra023075

Hersi HM, Raulf N, Gaken J et al (2018) MicroRNA-9 inhibits growth and invasion of head and neck cancer cells and is a predictive biomarker of response to plerixafor, an inhibitor of its target CXCR4. Mol Oncol 12:2023-2041. https://doi.org/10.1002/1878-0261.12352

Hu S, Wang H, Yan D et al (2018a) Loss of miR-16 contributes to tumor progression by activation of tousled-like kinase 1 in oral squamous cell carcinoma. Cell Cycle 17:2284-2295. https://doi. org/10.1080/15384101.2018.1526601

Hu X, Qiu Z, Zeng J et al (2018b) A novel long non-coding RNA, AC012456.4, as a valuable and independent prognostic biomarker of survival in oral squamous cell carcinoma. PeerJ 6:e5307. https:// doi.org/10.7717/peerj.5307

Huang C, Wang L, Song H, Wu C (2019) MiR-29a inhibits the progression of oral squamous cell carcinoma by targeting Wnt/ $\beta$-catenin signalling pathway. Artif Cells Nanomed Biotechnol 47:30373042. https://doi.org/10.1080/21691401.2019.1576712

Inoue K, Hano K, Bunai K et al (2018) Loss of ARID1A, a component of the SWI/SNF chromatin remodeling complex, at the invasion front is related to poor outcomes in oral squamous cell carcinoma. Oral Cancer 2:1-5. https://doi.org/10.1007/s41548-018-0003-2

Irani S (2016) miRNAs Signature in head and neck squamous cell carcinoma metastasis: a literature review. J Dent (Shiraz) 17:71-83

Jäwert F, Hasséus B, Kjeller G et al (2013) Loss of 5-hydroxymethylcytosine and TET2 in oral squamous cell carcinoma. Anticancer Res 33:4325-4328

Jili S, Eryong L, Lijuan L, Chao Z (2016) RUNX3 inhibits laryngeal squamous cell carcinoma malignancy under the regulation of miR-148a-3p/DNMT1 axis. Cell Biochem Funct 34:597-605. https ://doi.org/10.1002/cbf.3233

Kao Y-Y, Chou C-H, Yeh L-Y et al (2019) MicroRNA miR-31 targets SIRT3 to disrupt mitochondrial activity and increase oxidative stress in oral carcinoma. Cancer Lett 456:40-48. https://doi. org/10.1016/j.canlet.2019.04.028

Katayama A, Ogino T, Bandoh $\mathrm{N}$ et al (2007) Overexpression of small ubiquitin-related modifier-1 and sumoylated Mdm2 in oral squamous cell carcinoma: Possible involvement in tumor proliferation and prognosis. Int J Oncol 31:517-524. https://doi.org/10.3892/ijo.31.3.517

Kidani K, Osaki M, Tamura T et al (2009) High expression of EZH2 is associated with tumor proliferation and prognosis in human oral squamous cell carcinomas. Oral Oncol 45:39-46. https://doi. org/10.1016/J.ORALONCOLOGY.2008.03.016

Kim SY, Han YK, Song JM et al (2019) Aberrantly hypermethylated tumor suppressor genes were identified in oral squamous cell carcinoma (OSCC). Clin Epigenetics 11:116. https://doi.org/10.1186/ s13148-019-0715-0

Kimura S, Naganuma S, Susuki D et al (2010) Expression of microRNAs in squamous cell carcinoma of human head and neck and the esophagus: miR-205 and miR-21 are specific markers for HNSCC and ESCC. Oncol Rep 23:1625-1633

Kitkumthorn N, Mutirangura A (2011) Long interspersed nuclear element-1 hypomethylation in cancer: biology and clinical applications. Clin Epigenetics 2:315-330. https://doi.org/10.1007/s1314 8-011-0032-8

Kitkumthorn N, Keelawat S, Rattanatanyong P, Mutirangura A (2012) LINE-1 and Alu methylation patterns in lymph node metastases of head and neck cancers. Asian Pac J Cancer Prev 13:4469-4475 
Koffler J, Sharma S, Hess J (2014) Predictive value of epigenetic alterations in head and neck squamous cell carcinoma. Mol Cell Oncol 1:e954827. https://doi.org/10.1080/23723548.2014.954827

Kolenda T, Guglas K, Kopczyńska M et al (2019) Oncogenic role of ZFAS1 lncRNA in head and neck squamous cell carcinomas. Cells 8(4):E366. https://doi.org/10.3390/cells8040366

Kong J, Sun W, Zhu W et al (2018) Long noncoding RNA LINC01133 inhibits oral squamous cell carcinoma metastasis through a feedback regulation loop with GDF15. J Surg Oncol 118:1326-1334. https://doi.org/10.1002/jso.25278

Koutsimpelas D, Pongsapich W, Heinrich U et al (2012) Promoter methylation of MGMT, MLH1 and RASSF1A tumor suppressor genes in head and neck squamous cell carcinoma: pharmacological genome demethylation reduces proliferation of head and neck squamous carcinoma cells. Oncol Rep 27:1135-1141. https://doi.org/10.3892/or.2012.1624

Kumar B, Yadav A, Lang J et al (2012) Dysregulation of microRNA-34a expression in head and neck squamous cell carcinoma promotes tumor growth and tumor angiogenesis. PLoS ONE 7:e37601. https://doi.org/10.1371/journal.pone.0037601

Kumarasamy C, Madhav MR, Sabarimurugan S et al (2019) Prognostic value of miRNAs in head and neck cancers: a comprehensive systematic and meta-analysis. Cells 8:772. https://doi.org/10.3390/ cells 8080772

Kuo Y-Z, Tai Y-H, Lo H-I et al (2014) MiR-99a exerts anti-metastasis through inhibiting myotubularinrelated protein 3 expression in oral cancer. Oral Dis 20:e65-e75. https://doi.org/10.1111/odi.12133

Lachner M, Jenuwein T (2002) The many faces of histone lysine methylation. Curr Opin Cell Biol 14:286-298. https://doi.org/10.1016/S0955-0674(02)00335-6

Le J, Squarize CH, Castilho RM (2014) Histone modifications: Targeting head and neck cancer stem cells. World J Stem Cells 26:511-525. https://doi.org/10.4252/wjsc.v6.i5.511

Lee YS, Dutta A (2009) MicroRNAs in cancer. Annu Rev Pathol 4:199-227. https://doi.org/10.1146/ annurev.pathol.4.110807.092222

Leemans CR, Braakhuis BJM, Brakenhoff RH (2011) The molecular biology of head and neck cancer. Nat Rev Cancer 11:9-22. https://doi.org/10.1038/nrc2982

Li J, Huang H, Sun L et al (2009) MiR-21 indicates poor prognosis in tongue squamous cell carcinomas as an apoptosis inhibitor. Clin Cancer Res 15:3998-4008. https://doi.org/10.1158/1078-0432. CCR-08-3053

Li B, Wang B, Niu L-J et al (2011) Hypermethylation of multiple tumor-related genes associated with DMNT3b up-regulation served as a biomarker for early diagnosis of esophageal squamous cell carcinoma. Epigenetics 6:307-316. https://doi.org/10.4161/epi.6.3.14182

Li J, Gong P, Lyu X et al (2014a) Aberrant CpG island methylation of PTEN is an early event in nasopharyngeal carcinoma and a potential diagnostic biomarker. Oncol Rep 31:2206-2212. https://doi. org/10.3892/or.2014.3061

Li J, Huang Q, Zeng F et al (2014b) The prognostic value of global DNA hypomethylation in cancer: a meta-analysis. PLoS ONE 9:e106290. https://doi.org/10.1371/journal.pone.0106290

Li Z, Wang Y, Yuan C et al (2014c) Oncogenic roles of Bmil and its therapeutic inhibition by histone deacetylase inhibitor in tongue cancer. Lab Investig 94:1431-1445. https://doi.org/10.1038/labin vest.2014.123

Li G, Ren S, Su Z et al (2015) Increased expression of miR-93 is associated with poor prognosis in head and neck squamous cell carcinoma. Tumour Biol 36:3949-3956. https://doi.org/10.1007/s1327 7-015-3038-6

Li B, Wang W, Miao S et al (2019a) HOXA11-AS promotes the progression of oral squamous cell carcinoma by targeting the miR-518a-3p/PDK1 axis. Cancer Cell Int 19:140. https://doi.org/10.1186/ s12935-019-0838-6

Li Y, Tao C, Dai L et al (2019b) MicroRNA-625 inhibits cell invasion and epithelial-mesenchymal transition by targeting SOX4 in laryngeal squamous cell carcinoma. Biosci Rep. https://doi.org/10.1042/ BSR20181882

Liu C-J, Shen WG, Peng S-Y et al (2014) $m i R$-134 induces oncogenicity and metastasis in head and neck carcinoma through targeting WWOX gene. Int J Cancer 134:811-821. https://doi.org/10.1002/ ijc. 28358

Liu M-D, Wu H, Wang S et al (2018) MiR-1275 promotes cell migration, invasion and proliferation in squamous cell carcinoma of head and neck via up-regulating IGF-1R and CCR7. Gene 646:1-7. https://doi.org/10.1016/J.GENE.2017.12.049 
Lu W-C, Liu C-J, Tu H-F et al (2016) MiR-31 targets ARID1A and enhances the oncogenicity and stemness of head and neck squamous cell carcinoma. Oncotarget 7:57254-57267. https://doi. org/10.18632/oncotarget.11138

Lu T, Liu H, You G (2018) Long non-coding RNA C5orf66-AS1 prevents oral squamous cell carcinoma through inhibiting cell growth and metastasis. Int J Mol Med 42:3291-3299. https://doi. org/10.3892/ijmm.2018.3913

Lu Y, Huang W, Chen H et al (2019) MicroRNA-224, negatively regulated by c-jun, inhibits growth and epithelial-to-mesenchymal transition phenotype via targeting ADAM17 in oral squamous cell carcinoma. J Cell Mol Med 23:4913-4920. https://doi.org/10.1111/jcmm.14107

Luczak MW, Jagodziński PP (2006) The role of DNA methylation in cancer development. Folia Histochem Cytobiol 44:143-154

Luo M, Sun G, Sun J (2019) MiR-196b affects the progression and prognosis of human LSCC through targeting PCDH-17. Auris Nasus Larynx 46:583-592. https://doi.org/10.1016/J.ANL.2018.10.020

Magić Z, Supić G, Branković-Magić M, Jović N (2013) DNA methylation in the pathogenesis of head and neck cancer. In: Dricu A (ed) Methylation-from DNA, RNA and histones to diseases and treatment. InTech Open, Rijeka. https://doi.org/10.5772/51169

Mancuso M, Matassa DS, Conte M et al (2009) H3K4 histone methylation in oral squamous cell carcinoma. Acta Biochim Pol 56:405-410

Meng R-W, Li Y-C, Chen X et al (2016) Aberrant methylation of RASSF1A closely associated with HNSCC, a meta-analysis. Sci Rep 6:20756. https://doi.org/10.1038/srep20756

Meng W, Cui W, Zhao L et al (2019) Aberrant methylation and downregulation of ZNF667-AS1 and ZNF667 promote the malignant progression of laryngeal squamous cell carcinoma. J Biomed Sci 26:13. https://doi.org/10.1186/s12929-019-0506-0

Misawa K, Imai A, Mochizuki D et al (2018a) Association of TET3 epigenetic inactivation with head and neck cancer. Oncotarget 9:24480-24493. https://doi.org/10.18632/oncotarget.25333

Misawa K, Misawa Y, Imai A et al (2018b) Epigenetic modification of SALL1 as a novel biomarker for the prognosis of early stage head and neck cancer. J Cancer 9:941-949. https://doi. org/10.7150/jca.23527

Mochizuki D, Misawa Y, Kawasaki H et al (2018) Aberrant epigenetic regulation in head and neck cancer due to distinct EZH2 overexpression and DNA hypermethylation. Int J Mol Sci. https:// doi.org/10.3390/ijms19123707

Mohd-Sarip A, Teeuwssen M, Bot AG et al (2017) DOC1-dependent recruitment of NURD reveals antagonism with SWI/SNF during epithelial-mesenchymal transition in oral cancer cells. Cell Rep 20:61-75. https://doi.org/10.1016/J.CELREP.2017.06.020

Momen-Heravi F, Bala S (2018) Emerging role of non-coding RNA in oral cancer. Cell Signal 42:134-143. https://doi.org/10.1016/j.cellsig.2017.10.009

Momparler RL (2003) Cancer epigenetics. Oncogene 22:6479-6483. https://doi.org/10.1038/ sj.onc. 1206774

Morandi L, Gissi D, Tarsitano A et al (2017) CpG location and methylation level are crucial factors for the early detection of oral squamous cell carcinoma in brushing samples using bisulfite sequencing of a 13-gene panel. Clin Epigenetics 9:85. https://doi.org/10.1186/s1314 8-017-0386-7

Noguchi A, Li X, Kubota A et al (2013) SIRT1 expression is associated with good prognosis for head and neck squamous cell carcinoma patients. Oral Surg Oral Med Oral Pathol Oral Radiol 115:385-392. https://doi.org/10.1016/J.OOOO.2012.12.013

Onerci Celebi O, Tezel GG, Hosal AS et al (2016) Detection of O6-methylguanine-DNA methyltransferase gene promoter region methylation pattern using pyrosequencing and the effect of methylation pattern on survival, recurrence, and chemotherapy sensitivity in patients with laryngeal cancer. Pathol Res Pract 212:456-462. https://doi.org/10.1016/J.PRP.2016.02.022

Osorio JC, Castillo A (2016) Epigenetic mechanisms in head and neck cancer. In: Bulgin D (ed) New aspects in molecular and cellular mechanisms of human carcinogenesis. InTech, Rijeka. https:// doi.org/10.5772/61135

Padhi SS, Roy S, Kar M et al (2017) Role of CDKN2A/p16 expression in the prognostication of oral squamous cell carcinoma. Oral Oncol 73:27-35. https://doi.org/10.1016/J.ORALONCOLO GY.2017.07.030

Pannone G, Santoro A, Feola A et al (2014) The role of E-cadherin down-regulation in oral cancer: CDH1 gene expression and epigenetic blockage. Curr Cancer Drug Targets 14:115-127 
Park YJ, Claus R, Weichenhan D, Plass C (2011) Genome-wide epigenetic modifications in cancer. Prog Drug Res 67:25-49

Peng S-Y, Tu H-F, Yang C-C et al (2018) miR-134 targets PDCD7 to reduce E-cadherin expression and enhance oral cancer progression. Int J Cancer 143:2892-2904. https://doi.org/10.1002/ ijc. 31638

Puttipanyalears C, Subbalekha K, Mutirangura A, Kitkumthorn N (2013) Alu hypomethylation in smokeexposed epithelia and oral squamous carcinoma. Asian Pac J Cancer Prev 14:5495-5501

Qi G, Ogawa I, Kudo Y et al (2007) Aurora-B expression and its correlation with cell proliferation and metastasis in oral cancer. Virchows Arch 450:297-302. https://doi.org/10.1007/s00428-006-0360-9

Qin H, Xu J, Gong L et al (2019) The long noncoding RNA ST7-AS1 promotes laryngeal squamous cell carcinoma by stabilizing CARM1. Biochem Biophys Res Commun 512:34-40. https://doi. org/10.1016/J.BBRC.2019.02.057

Qiu X, Lei Z, Wang Z et al (2019) Knockdown of lncRNA RHPN1-AS1 inhibits cell migration, invasion and proliferation in head and neck squamous cell carcinoma. J Cancer 10:4000. https://doi. org/10.7150/JCA.29029

Qu L, Jin M, Yang L et al (2018) Expression of long non-coding RNA HOXA11-AS is correlated with progression of laryngeal squamous cell carcinoma. Am J Transl Res 10:573-580

Rasmussen KD, Helin K (2016) Role of TET enzymes in DNA methylation, development, and cancer. Genes Dev 30:733-750. https://doi.org/10.1101/gad.276568.115

Rastogi B, Raut SK, Panda NK et al (2016) Overexpression of HDAC9 promotes oral squamous cell carcinoma growth, regulates cell cycle progression, and inhibits apoptosis. Mol Cell Biochem 415:183-196. https://doi.org/10.1007/s11010-016-2690-5

Rather MI, Nagashri MN, Swamy SS et al (2013) Oncogenic microRNA-155 down-regulates tumor suppressor CDC73 and promotes oral squamous cell carcinoma cell proliferation: implications for cancer therapeutics. J Biol Chem 288:608-618. https://doi.org/10.1074/jbc.M1 12.425736

Reyngold M, Chan TA (2018) DNA methylation. In: Gelmann EP (ed) Molecular oncology: causes of cancer and targets for treatment. Cambridge University Press, Cambridge. https://doi.org/10.1017/ CBO9781139046947.006

Richards KL, Zhang B, Baggerly KA et al (2009) Genome-wide hypomethylation in head and neck cancer is more pronounced in HPV-negative tumors and is associated with genomic instability. PLoS ONE 4:e4941. https://doi.org/10.1371/journal.pone.0004941

Sakuma T, Uzawa K, Onda T et al (2006) Aberrant expression of histone deacetylase 6 in oral squamous cell carcinoma. Int J Oncol 29:117-124. https://doi.org/10.3892/ijo.29.1.117

Sanchez-Cespedes M, Esteller M, Wu L et al (2000) Gene Promoter Hypermethylation in Tumors and Serum of Head and Neck Cancer Patients. Cancer Res 60:892-895

Sassenberg M, Droop J, Schulz WA et al (2019) Upregulation of the long non-coding RNA CASC9 as a biomarker for squamous cell carcinoma. BMC Cancer 19:806. https://doi.org/10.1186/s1288 5-019-6021-6

Sauvageau M, Sauvageau G (2010) Polycomb group proteins: multi-faceted regulators of somatic stem cells and cancer. Cell Stem Cell 7:299-313. https://doi.org/10.1016/j.stem.2010.08.002

Scapoli L, Palmieri A, Lo ML et al (2010) MicroRNA expression profiling of oral carcinoma identifies new markers of tumor progression. Int J Immunopathol Pharmacol 23:1229-1234. https://doi. org/10.1177/039463201002300427

Selcuklu SD, Donoghue MTA, Spillane C (2009) $m i R-21$ as a key regulator of oncogenic processes. Biochem Soc Trans 37:918-925. https://doi.org/10.1042/BST0370918

Shen Z, Cao B, Lin L et al (2017) The clinical signification of Claudin-11 promoter hypermethylation for laryngeal squamous cell carcinoma. Med Sci Monit 23:3635-3640. https://doi.org/10.12659/ msm.904751

Shen Z, Hao W, Zhou C et al (2018) Long non-coding RNA AC026166.2-001 inhibits cell proliferation and migration in laryngeal squamous cell carcinoma by regulating the miR-24-3p/p27 axis. Sci Rep 8:3375. https://doi.org/10.1038/s41598-018-21659-5

Shen Z, Hu Y, Zhou C et al (2019) ESRRG promoter hypermethylation as a diagnostic and prognostic biomarker in laryngeal squamous cell carcinoma. J Clin Lab Anal. https://doi.org/10.1002/ jcla.22899

Shiiba M, Uzawa K, Tanzawa H (2010) MicroRNAs in head and neck squamous cell carcinoma (HNSCC) and oral squamous cell carcinoma (OSCC). Cancers (Basel) 2:653-669. https://doi. org/10.3390/cancers2020653 
Singh P, Srivastava AN, Sharma R et al (2018) Circulating microRNA-21 expression as a novel serum biomarker for oral sub-mucous fibrosis and oral squamous cell carcinoma. Asian Pac J Cancer Prev 19:1053-1057. https://doi.org/10.22034/APJCP.2018.19.4.1053

Smith IM, Mydlarz WK, Mithani SK, Califano JA (2007) DNA global hypomethylation in squamous cell head and neck cancer associated with smoking, alcohol consumption and stage. Int $\mathrm{J}$ Cancer 121:1724-1728. https://doi.org/10.1002/ijc.22889

Song C, Wang L, Wu X et al (2018) PML recruits TET2 to regulate DNA modification and cell proliferation in response to chemotherapeutic agent. Cancer Res 78:2475-2489. https://doi. org/10.1158/0008-5472.CAN-17-3091

Strzelczyk JK, Krakowczyk Ł, Owczarek AJ (2018) Aberrant DNA methylation of the p16, APC, MGMT, TIMP3 and CDH1 gene promoters in tumours and the surgical margins of patients with oral cavity cancer. J Cancer 9:1896-1904. https://doi.org/10.7150/jca.24477

Strzelczyk JK, Krakowczyk Ł, Owczarek AJ (2019) Methylation status of SFRP1, SFRP2, RASSF1A, RAR $\beta$ and DAPK1 genes in patients with oral squamous cell carcinoma. Arch Oral Biol 98:265272. https://doi.org/10.1016/J.ARCHORALBIO.2018.12.001

Subbalekha K, Pimkhaokham A, Pavasant P et al (2009) Detection of LINE-1s hypomethylation in oral rinses of oral squamous cell carcinoma patients. Oral Oncol 45:184-191. https://doi.org/10.1016/J. ORALONCOLOGY.2008.05.002

Supic G, Kozomara R, Zeljic K et al (2017) Prognostic value of the DNMTs mRNA expression and genetic polymorphisms on the clinical outcome in oral cancer patients. Clin Oral Investig 21:173182. https://doi.org/10.1007/s00784-016-1772-9

Sushma PS, Jamil K, Kumar PU et al (2016) PTEN and p16 genes as epigenetic biomarkers in oral squamous cell carcinoma (OSCC): a study on south Indian population. Tumor Biol 37:7625-7632. https://doi.org/10.1007/s13277-015-4648-8

Suzuki M, Shinohara F, Endo M et al (2009) Zebularine suppresses the apoptotic potential of 5-fluorouracil via cAMP/PKA/CREB pathway against human oral squamous cell carcinoma cells. Cancer Chemother Pharmacol 64:223-232. https://doi.org/10.1007/s00280-008-0833-4

Szaumkessel M, Wojciechowska S, Janiszewska J et al (2017) Recurrent epigenetic silencing of the PTPRD tumor suppressor in laryngeal squamous cell carcinoma. Tumor Biol 39:101042831769142. https://doi.org/10.1177/1010428317691427

Tachibana H, Sho R, Takeda Y et al (2016) Circulating miR-223 in oral cancer: Its potential as a novel diagnostic biomarker and therapeutic target. PLoS ONE 11:e0159693. https://doi.org/10.1371/ journal.pone.0159693

Tahiliani M, Koh KP, Shen Y et al (2009) Conversion of 5-methylcytosine to 5-hydroxymethylcytosine in mammalian DNA by MLL partner TET1. Science 324:930-935. https://doi.org/10.1126/scien ce. 1170116

Tan L, Shi YG (2012) Tet family proteins and 5-hydroxymethylcytosine in development and disease. Development 139:1895-1902. https://doi.org/10.1242/dev.070771

Tang K-L, Tang H-Y, Du Y et al (2019) MiR-638 suppresses the progression of oral squamous cell carcinoma through wnt/ $\beta$-catenin pathway by targeting phospholipase D1. Artif Cells Nanomed Biotechnol 47:3278-3285. https://doi.org/10.1080/21691401.2019.1647222

Tanzawa H, Uzawa K, Yokoe H et al (2008) PTEN expression and methylation status in oral squamous cell carcinoma. Oncol Rep 19:1429-1434. https://doi.org/10.3892/or.19.6.1429

Teodoridis JM, Strathdee G, Brown R (2004) Epigenetic silencing mediated by CpG island methylation: potential as a therapeutic target and as a biomarker. Drug Resist Updat 7:267-278. https://doi. org/10.1016/J.DRUP.2004.06.005

Thienpont B, Steinbacher J, Zhao H et al (2016) Tumour hypoxia causes DNA hypermethylation by reducing TET activity. Nature 537:63-68. https://doi.org/10.1038/nature19081

Valenti F, Sacconi A, Ganci F et al (2019) The miR-205-5p/BRCA1/RAD17 axis promotes genomic instability in head and neck squamous cell carcinomas. Cancers (Basel) 11:1347. https://doi. org/10.3390/cancers11091347

van Kempen PMW, van Bockel L, Braunius WW et al (2014) HPV-positive oropharyngeal squamous cell carcinoma is associated with TIMP3 and CADM1 promoter hypermethylation. Cancer Med 3:1185-1196. https://doi.org/10.1002/cam4.313

Veeramachaneni R, Walker T, Revil T et al (2019) Analysis of head and neck carcinoma progression reveals novel and relevant stage-specific changes associated with immortalisation and malignancy. Sci Rep 9:11992. https://doi.org/10.1038/s41598-019-48229-7 
Virani S, Bellile E, Bradford CR et al (2015) NDN and CD1A are novel prognostic methylation markers in patients with head and neck squamous carcinomas. BMC Cancer 15:825. https://doi. org/10.1186/s12885-015-1806-8

Vo DT, Karanam NK, Ding L et al (2019) miR-125a-5p functions as tumor suppressor microRNA and is a marker of locoregional recurrence and poor prognosis in head and neck cancer. Neoplasia 21:849-862. https://doi.org/10.1016/j.neo.2019.06.004

Vogt TJ, Gevensleben H, Dietrich J et al (2018) Detailed analysis of adenosine A2a receptor (ADORA2A) and CD73 (5'-nucleotidase, ecto, NT5E) methylation and gene expression in head and neck squamous cell carcinoma patients. Oncoimmunology. https://doi.org/10.1080/2162402X.2018.1452579

Wang KC, Chang HY (2011) Molecular mechanisms of long noncoding RNAs. Mol Cell 43:904-914. https://doi.org/10.1016/j.molcel.2011.08.018

Wang X, Li G-H (2018) MicroRNA-16 functions as a tumor-suppressor gene in oral squamous cell carcinoma by targeting AKT3 and BCL2L2. J Cell Physiol 233:9447-9457. https://doi. org/10.1002/jcp.26833

Wang GG, Allis CD, Chi P (2007a) Chromatin remodeling and cancer, part I: covalent histone modifications. Trends Mol Med 13:363-372. https://doi.org/10.1016/J.MOLMED.2007.07.003

Wang GG, Allis CD, Chi P (2007b) Chromatin remodeling and cancer, Part II: ATP-dependent chromatin remodeling. Trends Mol Med 13:373-380. https://doi.org/10.1016/j.molmed.2007.07.004

Wang Y, Hu H, Wang Q et al (2017) The level and clinical significance of 5-hydroxymethylcytosine in oral squamous cell carcinoma: An immunohistochemical study in 95 patients. Pathol Res Pract 213:969-974. https://doi.org/10.1016/J.PRP.2017.04.016

Wang L-L, Li H-X, Yang Y-Y et al (2018a) MiR-31 is a potential biomarker for diagnosis of head and neck squamous cell carcinoma. Int J Clin Exp Pathol 11:4339-4345

Wang W, Li X, Wang F, Sun X-Y (2018b) Effect of TET1 regulating MGMT on chemotherapy resistance of oral squamous cell carcinoma stem cells. J Cell Biochem 119:723-735. https://doi. org/10.1002/jcb.26236

Wang B, Zhao L, Chi W et al (2019a) Aberrant methylation-mediated downregulation of IncRNA SSTR5-AS1 promotes progression and metastasis of laryngeal squamous cell carcinoma. Epigenetics Chromatin 12:35. https://doi.org/10.1186/s13072-019-0283-8

Wang X, Li H, Shi J (2019b) LncRNA HOXA11-AS promotes proliferation and cisplatin resistance of oral squamous cell carcinoma by suppression of miR-214-3p expression. Biomed Res Int 2019:1-11. https://doi.org/10.1155/2019/8645153

Warta R, Herold-Mende C, Chaisaingmongkol J et al (2014) Reduced promoter methylation and increased expression of CSPG4 negatively influences survival of HNSCC patients. Int J Cancer 135:2727-2734. https://doi.org/10.1002/ijc.28906

Watanabe R, Wei L, Huang J (2011) mTOR signaling, function, novel inhibitors, and therapeutic targets. J Nucl Med 52:497-500. https://doi.org/10.2967/jnumed.111.089623

Webber LP, Wagner VP, Curra M et al (2017) Hypoacetylation of acetyl-histone H3 (H3K9ac) as marker of poor prognosis in oral cancer. Histopathology 71:278-286. https://doi.org/10.1111/ his. 13218

Wei J-W, Huang K, Yang C, Kang C-S (2017) Non-coding RNAs as regulators in epigenetics. Oncol Rep 37:3-9. https://doi.org/10.3892/or.2016.5236

Wei G-G, Guo W-P, Tang Z-Y et al (2019) Expression level and prospective mechanism of miRNA$99 a-3 p$ in head and neck squamous cell carcinoma based on miRNA-chip and miRNAsequencing data in 1, 167 cases. Pathol Res Pract 215:963-976. https://doi.org/10.1016/J. PRP.2019.02.002

Wen G, Wang H, Zhong Z (2018) Associations of RASSF1A, RAR $\beta$, and CDH1 promoter hypermethylation with oral cancer risk: A PRISMA-compliant meta-analysis. Medicine (Baltimore) 97:e9971. https://doi.org/10.1097/MD.0000000000009971

Wu J, Zhao W, Wang Z et al (2019) Long non-coding RNA SNHG20 promotes the tumorigenesis of oral squamous cell carcinoma via targeting miR-197/LIN28 axis. J Cell Mol Med 23:680-688. https:// doi.org/10.1111/jcmm.13987

Xu Z, Xi K (2019) LncRNA RGMB-AS1 promotes laryngeal squamous cell carcinoma cells progression via sponging miR-22/NLRP3 axis. Biomed Pharmacother 118:109222

$\mathrm{Xu} \mathrm{W}$, Zou H, Wei Z, et al (2019) Rh type C-glycoprotein functions as a novel tumor suppressor gene by inhibiting tumorigenicity and metastasis in head and neck squamous cell carcinoma. Aging (Albany, NY) 11:3601-3623. https://doi.org/10.18632/aging.102000 
Yan B, Fu Q, Lai L et al (2012) Downregulation of microRNA 99a in oral squamous cell carcinomas contributes to the growth and survival of oral cancer cells. Mol Med Rep 6:675-681. https:// doi.org/10.3892/mmr.2012.971

Yang Q-Q, Deng Y-F (2014) Long non-coding RNAs as novel biomarkers and therapeutic targets in head and neck cancers. Int J Clin Exp Pathol 7:1286-1292

Yang S, Wang J, Ge W, Jiang Y (2018) Long non-coding RNA LOC554202 promotes laryngeal squamous cell carcinoma progression through regulating miR-31. J Cell Biochem 119:6953-6960. https ://doi.org/10.1002/jcb.26902

Yu C, Wang Y, Li G et al (2018) LncRNA PVT1 promotes malignant progression in squamous cell carcinoma of the head and neck. J Cancer 9:3593-3602. https://doi.org/10.7150/jca.26465

Zeng M, Li F, Wang L et al (2018) Downregulated cytoplasmic polyadenylation element-binding protein-4 is associated with the carcinogenesis of head and neck squamous cell carcinoma. Oncol Lett 15:3226-3232. https://doi.org/10.3892/ol.2017.7661

Zhang J, Wang Y, Chen X et al (2015a) MiR-34a suppresses amphiregulin and tumor metastatic potential of head and neck squamous cell carcinoma (HNSCC). Oncotarget 6:7454-7469. https://doi. org/10.18632/oncotarget.3148

Zhang X-Y, Li M, Sun K et al (2015b) Decreased expression of GRIM-19 by DNA hypermethylation promotes aerobic glycolysis and cell proliferation in head and neck squamous cell carcinoma. Oncotarget 6:101-15. https://doi.org/10.18632/oncotarget.2684

Zhang Y, Wu K, Shao Y et al (2016) Decreased 5-Hydroxymethylcytosine (5-hmC) predicts poor prognosis in early-stage laryngeal squamous cell carcinoma. Am J Cancer Res 6:1089-1098

Zhang J, Shen Z, Liu H et al (2018a) Diagnostic potential of methylated DAPK in brushing samples of nasopharyngeal carcinoma. Cancer Manag Res 10:2953-2964. https://doi.org/10.2147/CMAR. S171796

Zhang Z, Wang X, Cao S et al (2018b) The long noncoding RNA TUG1 promotes laryngeal cancer proliferation and migration. Cell Physiol Biochem 49:2511-2520

Zhang J, Zheng Z, Zheng J et al (2019) Epigenetic-mediated downregulation of zinc finger protein 671 (ZNF671) predicts poor prognosis in multiple solid tumors. Front Oncol 9:342. https://doi. org/10.3389/fonc. 2019.00342

Zhao H, Chen T (2013) Tet family of 5-methylcytosine dioxygenases in mammalian development. J Hum Genet 58:421-427

Zheng J, Wang J, Jia Y et al (2018) microRNA-211 promotes proliferation, migration, and invasion ability of oral squamous cell carcinoma cells via targeting the bridging integrator 1 protein. J Cell Biochem 120:4644-4653

Zhong W, Xu Z, Wen S et al (2019) Long non-coding RNA myocardial infarction associated transcript promotes epithelial-mesenchymal transition and is an independent risk factor for poor prognosis of tongue squamous cell carcinoma. J Oral Pathol Med 48:720-727

Zhou C, Shen Z, Ye D et al (2018) The association and clinical significance of CDKN2A promoter methylation in head and neck squamous cell carcinoma: a Meta-analysis. Cell Physiol Biochem 50:868-882

Zhou C, Li J, Li Q et al (2019) The clinical significance of promoter hypermethylation in head and neck squamous cell carcinoma. J Clin Lab Anal 33:e22873. https://doi.org/10.1002/jcla.22873

Zhu S, Wu H, Wu F et al (2008) MicroRNA-21 targets tumor suppressor genes in invasion and metastasis. Cell Research 18(3):350-359

Publisher's Note Springer Nature remains neutral with regard to jurisdictional claims in published maps and institutional affiliations. 